\title{
PREFERENCIAS ALIMENTARIAS DE Apis mellifera L. EN EL CHACO SEMIHÚMEDO CENTRAL
}

\author{
Changazzo, Juliana A.; Salgado Laurenti, Cristina R. ${ }^{2}$ \\ Facultad de Ciencias Agrarias - UNNE \\ ${ }^{1}$ Tesista; ${ }^{2}$ Directora \\ Trabajo Final de Graduación para optar por el título de Ingeniera Agrónoma
}

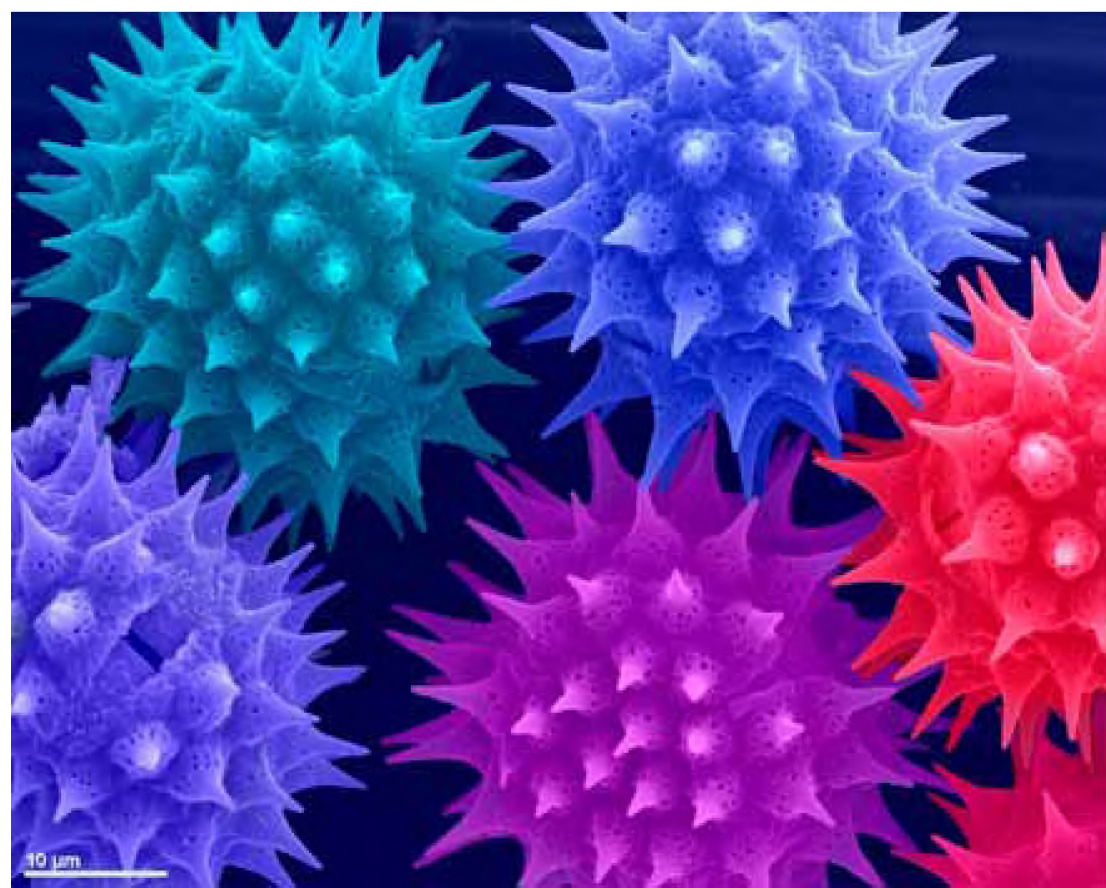

“Multicolored thorns”. Premio: Mención Especial. Categoría: Mas allá de los ojos. VI Concurso Nacional Fotográfico "Ciencia en Foco, tecnología en Foco". Concurso 2018. Organizado por la AGENCIA - MINCyT.

Los resultados preliminares del Trabajo Final de Graduación fueron presentados en los siguientes Congresos:

- XVII Simposio Argentino de Paleontología y Palinología. 30 de julio al 3 de agosto de 2018. Paraná, Entre Ríos. Argentina.

- XIII Congreso Latinoamericano de Apicultura. Federación Lationamericana de Apicultura. 2 al 5 de agosto de 2018. Montevideo, Uruguay.

- XXVI Reunión de Comunicaciones Científicas, Técnicas y de Extensión. Facultad de Ciencias Agrarias de la UNNE. 5 al 7 de septiembre de 2018. Corrientes. Argentina

\section{RESUMEN}

La relación insecto-planta es interesante de conocer, por cuanto nos revela las preferencias alimenticias de la abeja. El polen es la principal fuente de proteínas y lípidos para las abejas, es recogido con gran intensidad en el período primaveral para elaborar el "pan de las abejas" coincidiendo con el desarrollo de las larvas y el crecimiento de la colonia. El objetivo general de este trabajo fue conocer la variabilidad florística de las cargas polínicas aprovechadas por Apis mellifera en la localidad de General Pinedo, provincia del Chaco. Las muestras fueron tomadas semanalmente en el periodo apícola 2014 - 2015, se utilizaron trampas caza-polen colocadas en la entrada de 3 (tres) colmenas. Se procesaron, con la técnica de acetólisis, 18 muestras en total. Cada muestra fue pesada y luego fue deshidratada por el método de liofilizado para su conservación. Posteriormente, las muestras fueron separadas y clasificadas por color en 66 submuestras. Todas las observaciones, descripciones y análisis se realizaron con microscopio óptico Leica CME y se obtuvieron fotografías digitales de los granos de polen con la cámara Leica ICC50W del equipo Leica DM500 y con microscopio electrónico de ba- 
rrido JEOL 5800LV. Algunas cargas corbiculares fueron seleccionadas para evaluar su contenido de nitrógeno y proteína total mediante el Método Kjeldahl. Los resultados obtenidos fueron sometidos a análisis descriptivos y multivariados. Se realizaron análisis de componentes principales (PCA) y análisis de agrupamiento, utilizando distancia de Jaccard y el algoritmo UPGMA para la elaboración del dendrograma. Los resultados obtenidos mostraron que las preferencias de Apis estuvo representada por 31 taxa, de los cuales se identificaron 23 a nivel específico, 5 a nivel genérico, 2 a tipo polínico y 1 no pudo ser determinado taxonómicamente. Las familias vegetales identificadas fueron 18, las Fabaceae y Asteraceae fueron las mejor representadas en número de especies, en coincidencia con otras regiones fitogeográficas del país. El 81\% son especies nativas y el 19\% son exóticas. Los estudios de contenido proteico de las cargas corbiculares realizados en este trabajo aportan información acerca de la capacidad nutricional de las especies nativas. Finalmente, a partir de los resultados obtenidos resulta interesante y necesario continuar con estudios de esta temática para conocer detalladamente las propiedades nutricionales del polen que disponen las abejas de esta región.

Palabras clave: polen corbicular, Chaco, contenido proteico.

\section{SUMMARY}

Plant and insect have an interest relationship that is worth knowing, as it reveals bees' eating preferences. Pollen is the main proteins and lipids source for bees, it is picked up with great intensity during the spring period to elaborate the "bees' bread" coinciding with the development of larvae and the colony growth. The general objective of this work was to know the floristic variablility of pollen charges used by Apis mellifera in General Pinedo, located in province of Chaco. The samples were taken weekly during the beekeeping period $2014-2015$, pollen-hunting traps were used placed on the entrance of 3 (three) hives. A total of 18 samples were processed with the acetolysis technique. For their conservation, each sample was weight and then dehydrated using the lyophilisate method. Afterwards, samples were separated and classified according their colour in 66 subsamples. All observations, descriptions and analysis were made using a Leica CME optic microscope and digital photographs of the pollen grains were obtained with the Leica ICC50W camera of the Leica DM500 equipment and the JEOL 5800LV scanning electron microscope. Some corbicular pollen were selected to evaluate their content in nitrogen and total protein according to the Kjeldahl Method. The obtained results were subjected to descriptive and multivariate analyses. Principal components analysis (PCA) and grouping analysis were made, using Jaccard distance and the UPGMA algorithm to elaborate a dendrogram. The results showed Apis preferences represented by 31 taxa, 23 of which were identified to species level, 5 to genus level, 2 to pollen type and 1 was not able to be taxonomically determined. There were 18 identified vegetable families, Fabaceae and Asteraceae were the best represented in species number, which coincides with other phytogeographic regions of the country. A total of $81 \%$ are native species and $19 \%$ are exotic. The protein content studies of corbicular pollen accomplished in this work provide information about the nutritional capacity of native species. Finally, from the obtained results it is considered interesting and necessary to continue with studies on this subject, in order to know in detail the nutritional properties of pollen that bees in the region have.

Key words: corbicular pollen, Chaco, protein content.

\section{INTRODUCCIÓN}

Existe una estrecha relación entre la abeja melífera y la vegetación circundante al apiario, de la cual obtiene néctar y el polen para su alimentación. La relación insecto-planta es interesante de conocer, por cuanto nos revela las preferencias alimenticias de la abeja (Cook et al., 2003; Dimou et al., 2014).

La abeja melífera vive en estrecha relación con la vegetación circundante, de la que obtiene el néctar y el polen para su alimentación. Así, conociendo al mismo tiempo la vegetación de una zona, podremos valorar el aprovechamiento apícola de un territorio, tanto para la obtención de determinados productos, como para la polinización de cultivos. El polen, como fuente principal de proteínas y lípidos para las abejas, va a ser recogido con gran intensidad en el período primaveral para elaborar el "pan de las abejas" coincidiendo con el desarrollo de las larvas y el crecimiento de la colonia (Jean-Prost, 1989).

Analizando las cargas corbiculares se puede determinar qué grado de utilización de la flora disponible es aprovechada por las abejas, esto determina las preferencias alimenticias de las abejas que normalmente se corresponde sólo a una parte de la flora a su alcance. El análisis microscópico de las cargas de 
polen nos permite determinar cuáles son las especies preferidas por las abejas para alimentar a las larvas.

La localidad de General Pinedo se encuentra ubicada dentro de una amplia zona denominada Ecorregión Chaco Seco, y más específicamente dentro del área conocida como Complejo Subhúmedo Central (Morello et al., 2012). La apicultura es practicada por un buen número de pequeños productores con intenciones de diversificar su producción obteniendo polen comercial además de miel. En este sentido, este estudio permitirá dilucidar qué fuentes poliníferas son las más importantes en la zona.

En la provincia del Chaco se han realizado estudios palinológicos de muestras de miel (Chifa et al., 2000; Salgado, 2006; Salgado et al., 2014), físico químicos (Salgado y Maidana, 2014) y análisis sensoriales (Aguirre Rollet, 2017). Sin embargo, no existe referencia de trabajos referidos al origen floral de las cargas polínicas colectadas por las abejas y utilizadas como alimento de la cría.

Argentina es un importante país productor de mieles de alta calidad, en este sentido se dispone de numerosos registros bibliográficos respecto al estudio y caracterización botánica y geográfica de las mieles. Sin embargo, los estudios sobre flora apícola y polen corbicular son escasos y están limitados principalmente al centro del país (Tellería, 1993, 1995; Gurini y Basilio, 1995; Basilio, 2000; Forcone, 2002; Andrada, 2003; Andrada et al., 2004; Andrada y Tellería, 2005; Naab y Tamame, 2007; Naab y Ponce, 2001).

Si bien la región Pampeana es la mayor productora en materia de Apicultura, en los últimos 20 años el Nordeste Argentino ha crecido significativamente en productores y número de colmenas incrementando el volumen de producción principalmente de miel. En este sentido se realizaron estudios palinológicos de muestras de miel de varias provincias de la Región NE (Cabrera, 2006; Chifa et al., 2000; Salgado y Pire, 1998, 1999; Salgado, 2006; Salgado et al., 2014, 2017), físico químicos (Salgado y Maidana, 2014, Salgado, 2016) y análisis sensoriales (Aguirre Rollet, 2017).

En la zona existen condiciones apropiadas para la obtención de otros productos de la colmena, por ejemplo polen comercial. Debido a que aún no existen grandes producciones de polen, las referencias de trabajos de cargas polínicas son escasas. Un estudio previo, mostró una interesante variedad de especies, principalmente nativas, correspondientes a familias angiospérmicas tales como: Achatocarpaceae, Asteraceae, Boraginaceae, Brassicaceae, Euphorbiaceae, Fabaceae, Solanaceae, entre otras.

\section{Objetivo general}

Conocer la variabilidad florística de las cargas polínicas aprovechadas por Apis mellifera en la localidad de General Pinedo, provincia del Chaco.

\section{Objetivos particulares}

Determinar el origen botánico de la oferta de polen durante la curva de floración de primavera y verano.

Detectar cuáles son las preferencias botánicas de las abejas respecto de la oferta de polen en la época invernal.

\section{Hipótesis de trabajo [H]}

$[\mathbf{H}]-1$. El color de las cargas polínicas está relacionado con su origen botánico.

[H]-2. La variabilidad de especies en las cargas de polen colectadas por las abejas está relacionada con los momentos de la curva de floración.

\section{MATERIALES Y MÉTODOS}

Las actividades se organizaron en tres grupos, que se describen a continuación:

\section{Trabajo de Campo}

1.a. Listado de especies en flor. Se consultó la bibliografía disponible para tener conocimiento de las especies en flor en el apiario utilizado para realizar el muestreo (Salgado, 2006; Salgado et al., 2014).

1.b. Muestreo de cargas polínicas. Las muestras fueron tomadas semanalmente desde el mes de septiembre a diciembre de 2014 y desde enero a abril 2015, para ello se utilizaron trampas caza-polen colocadas en la piquera de 3 (tres) colmenas. Se utilizó un apiario ubicado en la localidad de General Pinedo (provincia del Chaco).

\section{Trabajo de Laboratorio.}

2.a. Procesamiento de muestras. Se procesaron 18 muestras en total, cada muestra fue pesada y luego fue deshidratada por el método de liofilizado para su conservación, se estimó el peso final y luego fueron colocadas en freezer (Lám. 1. A). Posteriormente, las muestras fueron separadas y clasificadas por color en 66 submuestras, en base a la cartilla propuesta en http://www.sheffieldbeekeepers.org.uk/tools/pollenchart/.

2.b. Procesamiento de polen y obtención de preparados. Las muestras de polen que fueron clasificadas por color se procesaron individualmente. Para obtener la mayor información posible, el procesamiento de las muestras se procedió de dos maneras:

Procedimiento 1: se analizaron cargas corbiculares individuales seleccionadas por color, para determinar si son cargas mixtas o pertenecen a un solo recurso floral (Lám. 1. B).

Procedimiento 2: se tomaron varias cargas de distintos colores de la muestra total. En el preparado obtenido se contaron entre 300 y 700 granos de polen, dependiendo principalmente del carácter pluri-o monofloral de la muestra total (Lám. 1. C). 
Los granos de polen de ambos procedimientos fueron sometidos a la técnica de acetólisis (Erdtman, 1960) montados en preparaciones permanentes, incluidas en gelatina glicerina y sellados con parafina (Lám. 1. D, F, G, H). Todas las observaciones, descripciones y análisis se realizaron con microscopio óptico Leica CME. Para realizar las descripciones de los granos de polen se utilizó la terminología sugerida por Punt et al. (2007). Se obtuvieron fotografías digitales de los granos de polen con la cámara Leica ICC50W del equipo Leica DM500.

Además, se realizaron preparaciones temporarias para su observación y registro fotográfico con $\mathrm{mi}$ croscopio electrónico de barrido JEOL 5800LV.

2.c. Evaluación del contenido proteico. Fueron seleccionadas cargas corbiculares pertenecientes a 13 especies para evaluar su contenido de nitrógeno y proteína total mediante el Método Kjeldahl. Se seleccionaron teniendo en cuenta que la frecuencia de aparición en la muestra total fuera: Dominante o Secundario (Louveaux et al., 1978).

\section{Trabajo de Gabinete.}

3.a. Análisis cualitativo. El análisis cualitativo de mieles indica la diversidad polínica que posee la muestra o espectro polínico (Maurizio y Louveaux 1965, Louveaux et al. 1978). La identificación taxonómica de los tipos polínicos se realizó por comparación con preparados de referencia de la flora melífera del Chaco presentes en la Palinoteca de la UNNE (PAL-CTES) y con ilustraciones de Atlas Palinológicos (Markgraf y D'Antoni, 1978, Pire et al., 1992, 1994, 1998, 2001, 2006, 2013). Las determinaciones se realizaron a nivel de especie, género o familia.

Preparados del procedimiento 1. Las mediciones se realizaron en 20 granos de polen y se midieron los siguientes parámetros: eje polar $(\mathrm{P})$, diámetro ecuatorial $(E)$, aperturas, exina y elementos escul-

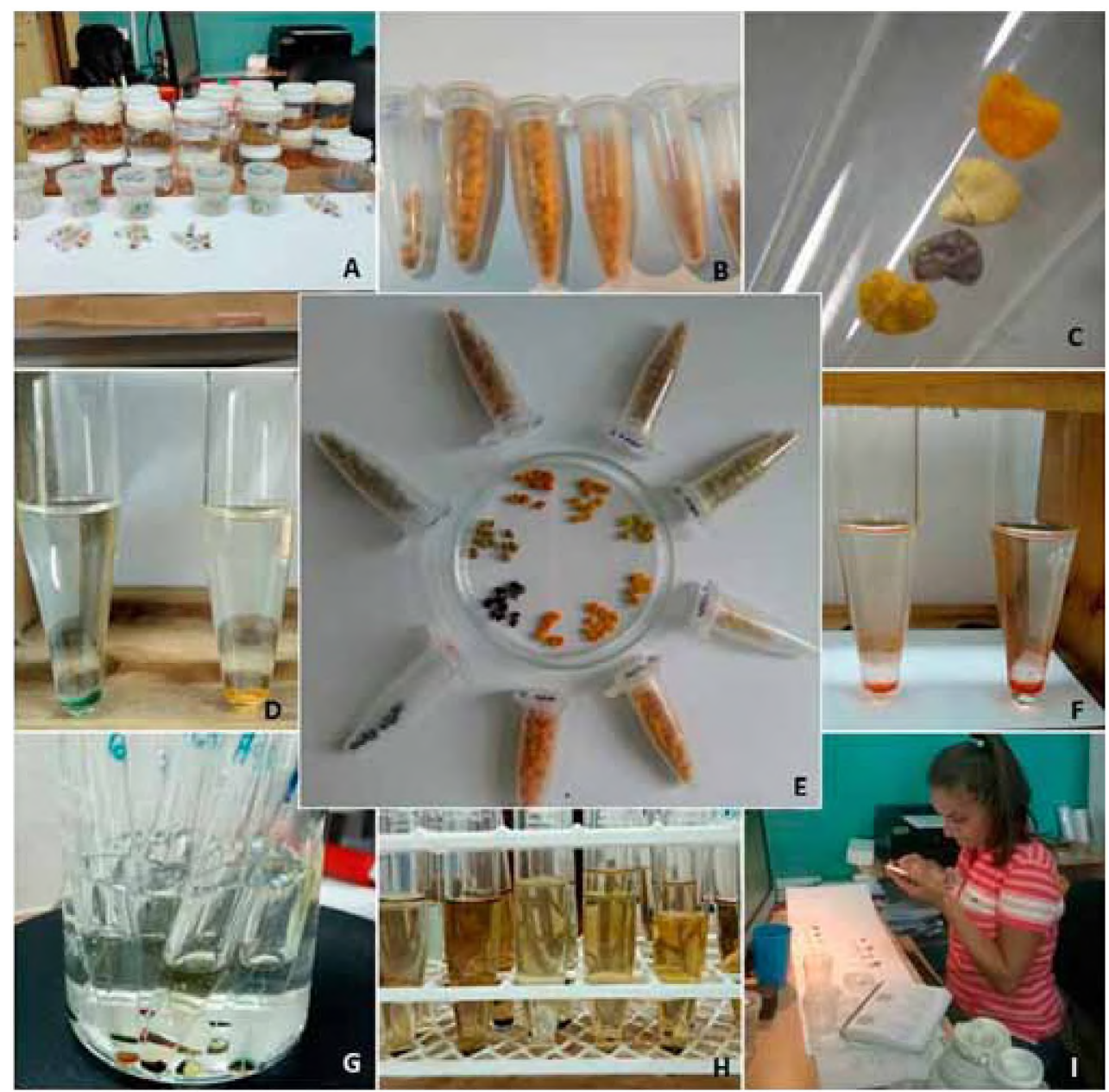

Lámina 1. Etapas del procesamiento de las cargas corbiculares. A. Muestras semanales. B. Submuestras de polen de Helianthus annuus. C. Cargas de diferentes colores de la muestra total. D y F. Cambio de color de los granos de polen en contacto con el ácido acético (reacción química), D. de izquierda a derecha: naranja a verde en tipo Bacharis-Eupatorium, amarrillo a amarrillo brillante en tipo-Croton. F. De izquierda a derecha; amarrillo y beige a naranja en Sphaeralcea bonariensis. E. Muestrario de la diversidad de colores hallada. G. Muestras en baño a $100^{\circ} \mathrm{C}$ - etapa del proceso de acetólisis. H. Color de las muestras después del proceso de acetólisis. I. Clasificación de las muestras en submuestras por tonalidad y color. 
turas (e.g. espinas). Los resultados obtenidos fueron cargados en tablas de Excel para realizar cálculos de estadística descriptiva para completar las descripciones morfológicas de cada especie determinada. Los valores utilizados fueron: rango de tamaño (valores Mínimos y máximos), desvío estándar y moda.

Preparados del procedimiento 2. Se contaron y clasificaron por especie, aproximadamente 500 granos de polen por muestra. Una vez finalizado el conteo, los resultados fueron cargados a una planilla de Excel para calcular los porcentajes relativos de cada tipo polínico dentro de la muestra. Se calcularon los porcentaje relativo a la cantidad de polen contado y se establecieron los rangos de frecuencia: Dominante (D), Secundario (S), de Menor Importancia (M) y en Traza (T). Posteriormente se determinaron las clases de frecuencia según Louveaux et al. (1978).

3.b. Análisis estadístico. Los resultados obtenidos fueron sometidos a análisis descriptivos y multivariados. Todos los datos generados fueron cargados en tablas de Excel y luego analizados estadísticamente. Con la matriz de abundancia relativa (porcentajes) de los tipos polínicos encontrados se realizaron análisis de componentes principales (PCA) y análisis de agrupamiento, utilizando distancia de Jaccard y el algoritmo UPGMA para la elaboración del dendrograma.

\section{RESULTADOS}

El análisis de las muestras permitió determinar los granos de polen en distintos categorías taxonómicas: veintitrés (23) a nivel especifico, cinco (5) a nivel genérico, dos (2) a tipo-polínico y un (l) taxa no pudo ser determinado (Fig. 1).

Las familias que presentaron la mayor cantidad de taxa fueron las Fabaceae $(7$ taxa $=23 \%)$ y Asteraceae (5 taxa $=17 \%$ ), algunas con solo dos (2) taxa, tales como: Euphorbiaceae (7\%) y Anacardiaceae $(7 \%)$. El $46 \%$ restante estuvo representado por familias con un solo taxa: Achatocarpaceae, Boraginaceae, Brassicaceae, Cactaceae, Cannabaceae, Capparidaceae, Malvaceae, Meliaceae, Nyctaginaceae, Poaceae, Polygonaceae, Rubiaceae, Rutaceae y Verbenaceae (Fig. 2).

Fue identificado un total de 31 taxa (Fig. 3), los mismos correspondieron principalmente a especies nativas $(81 \%)$ y un número menor perteneció a especies exóticas (19\%), distribuidos en dieciocho (18) familias vegetales.

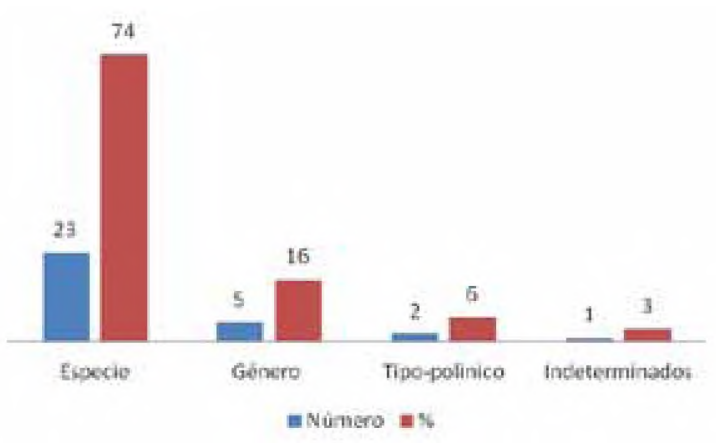

Figura 1. Nivel de identificación de los taxa registrados en las muestras.

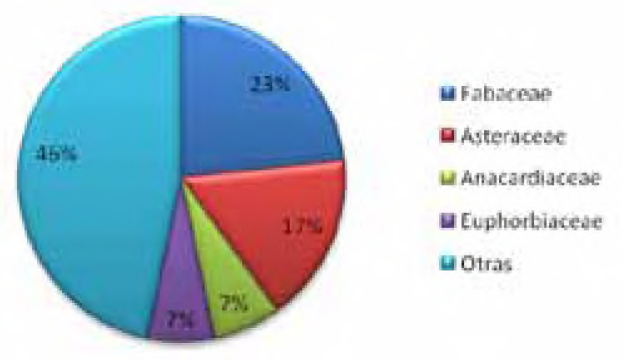

Figura 2. Familias botánicas representadas en las muestras de cargas corbiculares.

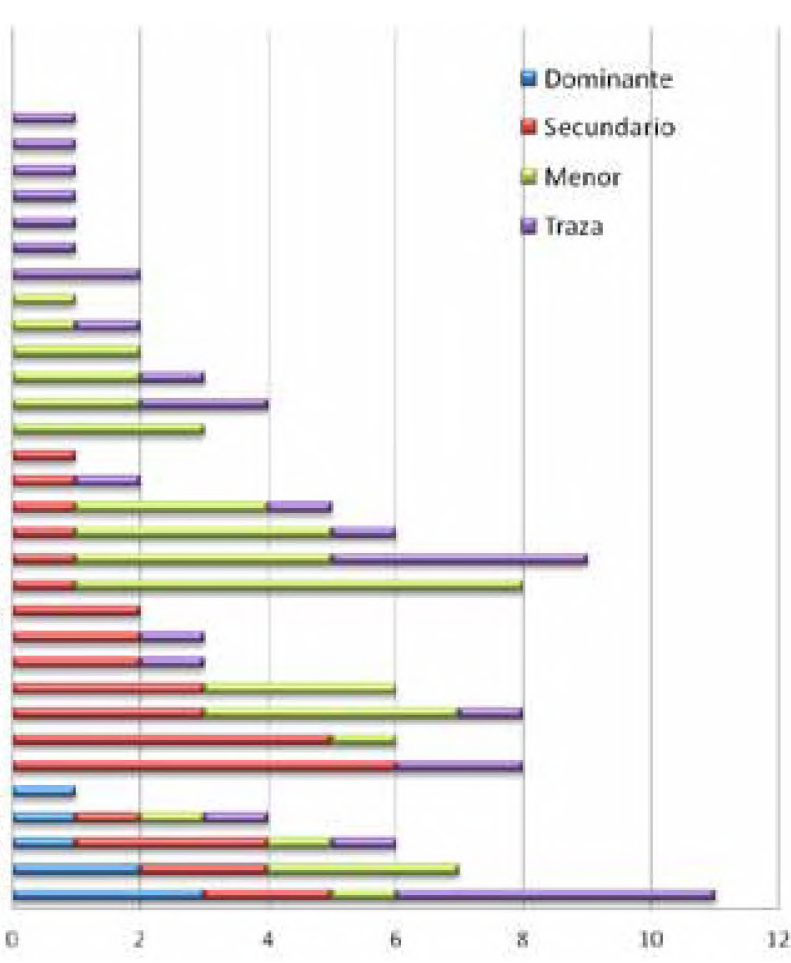

Figura 3. Frecuencia de aparición y clases de frecuencia de los taxa registrados en las muestras de cargas corbiculares. El asterisco indica las especies exóticas.

\section{Descripción morfológica de los granos de polen}

La morfología del polen de las distintas especies registradas en las cargas polínicas se resumen en la Tabla 1, en la cual se exponen los valores mínimos y máximos de las mediciones de los siguientes pará- 
Tabla 1: Características morfológicas de los granos de polen de las especies identificadas en las cargas corbiculares.

\begin{tabular}{|c|c|c|c|c|c|c|c|c|c|c|c|c|c|c|}
\hline \multirow{2}{*}{ Familia } & \multirow{2}{*}{ Especie } & \multirow{2}{*}{$\begin{array}{l}\text { Diámetro } \\
\text { Min-Max }\end{array}$} & \multicolumn{2}{|c|}{$\mathrm{P} \mu \mathrm{m}$} & \multicolumn{2}{|c|}{$E \mu \mathrm{m}$} & \multicolumn{2}{|c|}{$P / E$} & \multirow{2}{*}{ Forma } & \multicolumn{2}{|c|}{ Aperturas } & \multicolumn{3}{|c|}{ Exina } \\
\hline & & & Min & Max & Min & Max & Min & Max & & Número & Colpo $(\mu \mathrm{m})$ & Espesor & Estructura & Escultura \\
\hline Achatocarpaceae & Achatocarpus praecox $\{2\}\{6\}$ & $22-25$ & & & & & & & Esferoidales & 5 a 6 & & 1 & Tectada & Rugulada \\
\hline Anacardiaceae & Schinus molle & & 18 & 30 & 21 & 28 & 80 & 110 & Prolato esferoidales a Oblatos & 3 & & 1,5 & Semitectada & Microreticulada \\
\hline Anacardiaceae & Schinopsis lorentzii & & 29 & 32 & 28 & 32 & 94 & 114 & Esferoidales & 3 & $20-26$ & 2 & Semitectada & Reticulada \\
\hline \multirow[t]{5}{*}{ Asteraceae } & Helianthus annuus $\{9\}$ & & 32 & 34 & 30 & 32 & 100 & 113 & Esferoidales & 3 & $13-15$ & 1 & Tectada & Equinada \\
\hline & Senecio grisebachii $\{9\}$ & & 25 & 30 & 23 & 28 & 100 & 122 & Esferoidales & 3 & $17-19$ & 3 & Tectada & Equinada \\
\hline & Taxaracum sp. $\{10\}$ & & 24 & 28 & 24 & 28 & 100 & 110 & Esferoidales & 3 & & 1,5 & Semitectada & Lofada \\
\hline & tipo Baccharis-Eupatorium $\{10\}$ & & 16 & 22 & 15 & 20 & 100 & 127 & Esferoidales & 3 & 5,8 & 1 & Tetada & Equinada \\
\hline & Verbesia sp. $\{9\}$ & & 22 & 25 & 20 & 25 & 100 & 110 & Esferoidales & 3 & & 5 & Tectada & Equinada \\
\hline Boraginaceae & Echuim plantagineum $\{3\}$ & & 18 & 22 & 15 & 18 & 111 & 138 & Prolatos & 3 & & 1 & Tectada & Suprareticulada \\
\hline Brasicaceae & Brassicanapus $\{7\}$ & & 20 & 24,5 & 20 & 27 & 74 & 108 & Suboblato a prolato & 3 & 11,17 & 2 & Semitectada & Reticulada \\
\hline Cactaceae & Opuntia quimilo $\{2\}\{6\}$ & $98-122$ & & & & & & & Esferoidales & 8 a 10 & & 2 & Semitectada & Reticulada \\
\hline Cannabaceae & Celtis tala $\{6\}$ & & 16 & 23 & 21 & 25 & 64 & 88 & Suboblatos a oblatos & 3 & & 1 & Tectada & Psilada \\
\hline Capparidaceae & Cynophalla retusa $\{8\}\{11\}$ & & 23 & 32 & 21 & 24 & 110 & 150 & Prolato esferoidales & 3 & & 1 & Tectada & Espinulada \\
\hline \multirow[t]{2}{*}{ Euphorbiaceae } & Sapium haematospermum & & 50 & 60 & 35 & 41 & 132 & 167 & Prolatos & 3 & $40-50$ & 2 & Tectada & Perforada \\
\hline & tipo-Croton $\{2\}$ & $39-44$ & & & & & & & Esferoidales & - & & 3 & Atectada & Baculada \\
\hline \multirow[t]{7}{*}{ Fabaceae } & Acacia aroma $\{1\}\{4\}\{6\}$ & & 40 & 50 & 36 & 45 & 29 & 35 & Poliades & $64(4 c / u)$ & & 0 & Tectada & Escabrada \\
\hline & Erythrina crista-galli $\{6\}$ & & 17 & 25 & 25 & 31 & 57 & 96 & Oblatos & 3 & & 1 & Tectada & Supra-reticulada \\
\hline & Gleditzia amarphoides $\{8\}$ & & 25 & 32 & 20 & 29 & 103 & 145 & Esferoidales & 3 & $18-25$ & 2 & Semitectada & Reticulada \\
\hline & Glycine max & & 18 & 21 & 18 & 20 & 95 & 100 & Esferoidales & 3 & & 1 & Tectada & Supra-reticulada \\
\hline & Prosopis alba & & 25 & 30 & 20 & 39 & 72 & 150 & Esferoidales & 3 & $27-32$ & 1,5 & Tectada & Psilada \\
\hline & Prosopis ruscifolia $\{12\}$ & & 40 & 49 & 37 & 48 & 89 & 126 & Prolatos & 3 & $28-35$ & 2 & Tectada & Escabrada \\
\hline & Prosopis sp. & & 43 & 52 & 30 & 45 & 111 & 143 & Suboblatos a subprolatos & 3 & $35-43$ & 5 & Tectada & Psilada \\
\hline Malvacea & Sphaeralcea bonaeriensis $\{9\}$ & & 31 & 39 & 36 & 45 & 80 & 100 & Oblato esferoidales & 3 & & 1 & Tectada & Equinada \\
\hline Meliaceae & Melia azedarach & & 40 & 49 & 37 & 48 & 89 & 126 & Prolato esferoidales & 4 & $28-35$ & 2 & Tectada & Psilada \\
\hline Nintaginaceae & Pisonia zapallo $\{7\}\{8\}\{11\}$ & & 28 & 34 & 28 & 38 & 100 & 110 & Esferoidales & 3 & & 2 & Tectada & Equinulada-perforada \\
\hline Indeterminado & $\{8\}$ & & 53 & 65 & 30 & 46,5 & 123 & 203 & Prolato esferoidadles a prolato & 3 & $39-55$ & 2 & Tectada & Estriada \\
\hline Poaceae & Zeamays $\{3\}\{6\}$ & $31-46$ & & & & & & & Esferoidales & 1 & & 1 & Tectada & Psilada \\
\hline Poligonaceae & Polygonum hydropiperoides $\{2\}\{5\}\{6\}$ & $60-68$ & & & & & & & Esfeoidales & 10 a 14 & & 5 & Semitectada & Reticulada \\
\hline Rubiaceae & Borreria verticillata $\{10\}$ & & 24 & 39 & 29 & 33 & 80 & 93 & Suboblatos a oblato esferoidales & 8 & 10,15 & 2,5 & Tectada & Perforada-equinulada \\
\hline Rutaceae & Citrus sp. & & 28 & 35 & 29 & 33 & 88 & 117 & Prolatos a esferoidales & 4 & $19-25$ & 2 & Semitectada & Reticulada \\
\hline Verbenaceae & Aloysa sp. $\{12\}$ & & 21 & 25 & 23 & 25 & 80 & 100 & Esferoidales & 3 & $20-23$ & 1,5 & Tectada & Escabrada \\
\hline
\end{tabular}

Referencias:

$\{1\}$ Esta especie se dispersa en modo de poliade, el resto de las especies se dispersa en forma de nómade.

$\{2\}$ No presentan polaridad y $\{3\}$ son heteropolares, las demás especies son isopolar.

$\{4\}$ Presentan simetría basimetrica, $\{5\}$ son asimétricas y el retso de las especias son radiosimetricas.

Con respecto al tipo de apertura, las especies $\{6\}$ presentan poros, las $\{7\}$ colpos y las demás presentan colporos.

G. Las especies $\{8\}$ presentan una membrana apertural granulada.

Hay especies como $\{9\}$ que presentan espinas como elementos supractectales, las $\{10\}$ espinulas, las $\{11\}$ nanoespinulas y las $\{12\}$ granulos. 


\section{Clave dicotómica para el reconocimiento del polen de las especies poliniferas del Chaco Seco.}

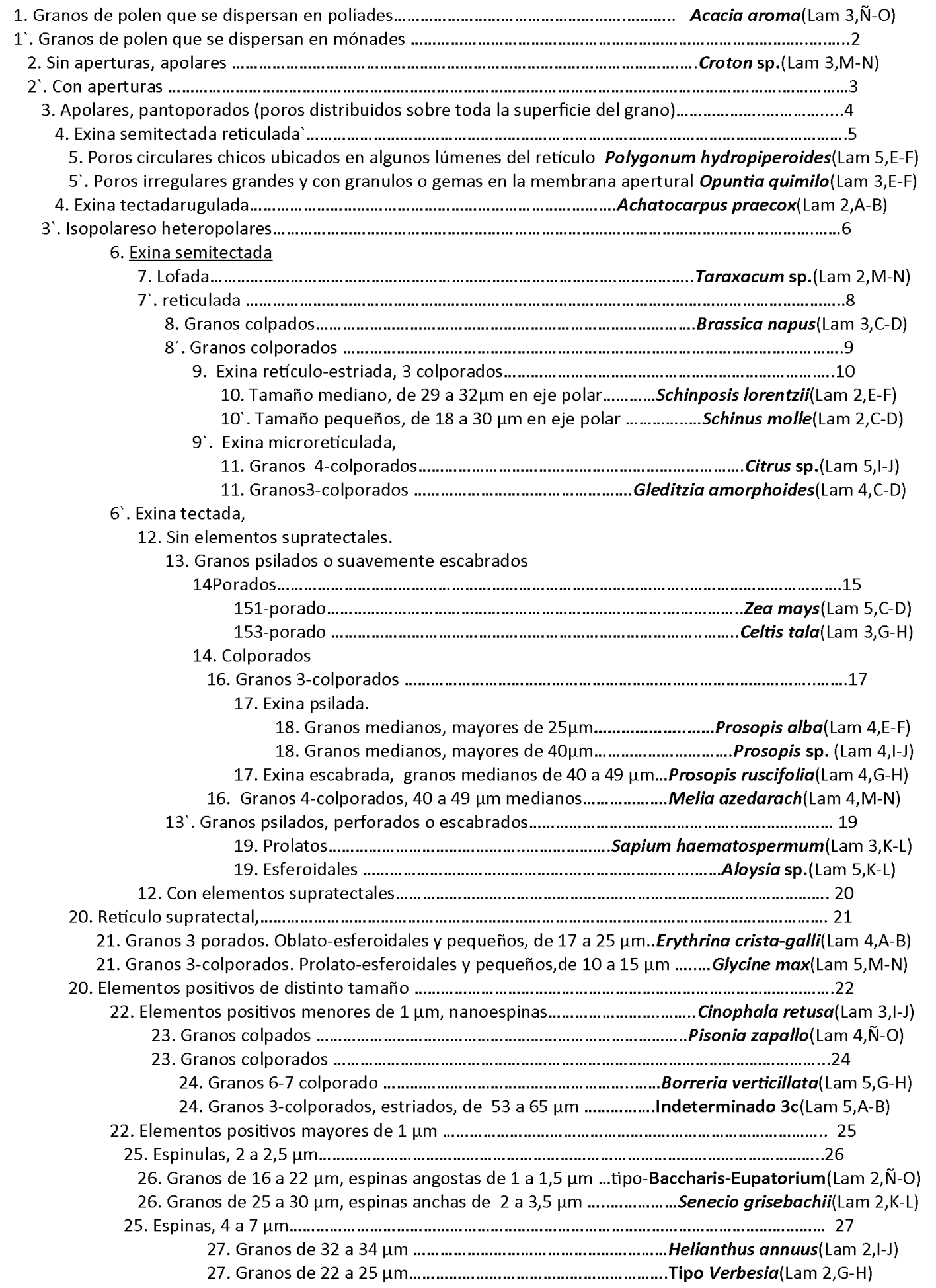

metros: en los granos de polen apolares se midió el diámetro (D), en los granos de polen con polaridad definida se midieron: eje polar (P), diámetro ecuatorial (E) y se calculó P/E para definir la forma de los mismos. Además, se detalla el tipo de unidad de dispersión, polaridad y simetría. Sobre la base de estas descripciones se pudo confeccionar una Clave dicotómica para su reconocimiento en muestras de polen colectado por abejas. Las especies más representa- tivas se encuentran ilustradas con fotografías tomadas con microscopia óptica y electrónicas de barrido (Anexo: Ilustraciones 1, 2, 3 y 4).

\section{Relación entre el origen floral y el color de las cargas corbiculares}

En la Tabla 2 se presentan las especies identificadas en las submuestras previamente clasificadas por color, a las que se les asignó nombres de los colores tomados 
Tabla 2. Origen botánico y color de las cargas corbiculares. El asterisco indica las especies exóticas.

\begin{tabular}{|c|c|c|c|c|}
\hline Familia & Especie & \multicolumn{3}{|c|}{ Color } \\
\hline Achatocarpaceae & Achatocarpus praecox & & BLUE CROCUS & \\
\hline \multirow[t]{2}{*}{ Anacardiaceae } & Shinus molle & & & \\
\hline & Schinopsis lorentzii & POOPLE & & \\
\hline \multirow[t]{5}{*}{ Asteraceae } & Taraxacum sp. & WILLOW & & \\
\hline & Helianthus annuus * & \multicolumn{2}{|l|}{ COMMON LIME } & \\
\hline & Senecio grisebachii & & YELLOW CROCUS & BLUEBELL PLANTAIN \\
\hline & tipo Baccharis - Eupatorium & DOGWOOG & FLOWER CURRANT & WILD HONEY SUCLDE \\
\hline & Verbesia sp. & & & \\
\hline Boraginaceae & Echium plantagineum ${ }^{*}$ & \multicolumn{2}{|c|}{ RED HORSE CHESTNUT } & \\
\hline Brassicaceae & Brassica napus * & BROCOLI & \multicolumn{2}{|l|}{ HIMALAYAN BALSAM } \\
\hline Cactaceae & Opuntia quimilo & BALSAME & & \\
\hline Cannabaceae & Celtis tala & & BLUE CROCUS & \\
\hline Capparidaceae & Cynophalla retusa & & & \\
\hline \multirow[t]{7}{*}{ Fabaceae } & Acacia aroma & & & WILD HONEY SUCLDE \\
\hline & Erythrina crista-galli & BROADBEAN & & \\
\hline & Gleditzia amorphoides & & \multicolumn{2}{|l|}{ HIMALAYAN BALSAM } \\
\hline & Glycine $\max *$ & & & \\
\hline & Prosopis alba & \multicolumn{2}{|c|}{ HIMALAYAN BALSAM } & WILD HONEY SUCLDE \\
\hline & Prosopis sp. & & LING HEATHER & \\
\hline & Prosopis ruscifolia & & \multicolumn{2}{|l|}{ FLOWER CURRANT } \\
\hline \multirow[t]{2}{*}{ Euphorbiaceae } & Sapium haematospermum & APPLE CABBAGE & & \\
\hline & Croton sp. & & WALLFLOWER & BLUEBELL PLANTAIN \\
\hline Malvaceae & Sphaeralcea bonariensis & & ONION & HAIRY WILLOWHERB \\
\hline Meliaceae & Melia azedarach * & & LING HEATHER & \\
\hline Nyctaginaceae & Pisonia zapallo & & & \\
\hline Polygonaceae & Polygonum hydropiperoides & & & \\
\hline Poaceae & Zea mays* & BOR & & \\
\hline Rubiaceae & Borreria verticillata & RASPBERRY & & \\
\hline Rutaceae & Citrus sp. ${ }^{*}$ & IVY & & \\
\hline Verbenacea & Aloysia sp. & & & \\
\hline Indeterminado & Indeterminado $3 c$ & MARJOMAN & & \\
\hline
\end{tabular}

de un muestrario adaptado a este fin (ver http://www. sheffieldbeekeepers.org.uk/tools/pollen-chart/).

Al analizar el polen de cargas corbiculares en forma individual y clasificada por color se corroboró que pertenecían a una sola especie, es decir eran monofloras o monoespecíficas (Lam. 2, A-B). Sin embargo, al procesar y analizar varias cargas de la misma muestra se registraron especies que no habían sido identificadas utilizando el criterio de clasificación por color (Lam. 2, C-D).

La mayoría de las especies presentaron un color de polen particular (Anexo: Ilustración 5). Sin embargo se presentaron algunas excepciones y diferentes combinaciones. Algunas especies presentaron dos colores diferentes (e.g. Sphaeralcea bonaeriensis, Brassica napus, Sapium haematospermum, tipo Croton y Prosopis alba) (Anexo: Ilustración 6). Una especie estuvo representada por tres colores (Tipo BaccharisEupatorium) (Anexo: Ilustración 6, M a N) y a su vez presentaron el mismo color: Achatocarpus praecox y Celtis tala (Anexo: Ilustración 7, A y B) y Prosopis sp. y Melia azedarach (Anexo: Ilustración 7, C y D).

\section{Variación mensual del origen floral}

El registro de muestras incluyó siete meses, desde septiembre de 2014 hasta abril de 2015. Se obtuvieron desde 4 muestras en octubre y noviembre, 3 en septiembre y diciembre, 2 en febrero y 1 en los meses de marzo y abril. Algunas especies fueron registradas en un número mayor de cargas corbiculares muestreadas en diferentes meses, lo que indica que la especie posee un periodo de floración más extenso y el recurso es aprovechado por las abejas durante más tiempo (Tabla 3). Los meses que mostraron mayor diversidad de taxa en las muestras obtenidas, fueron septiembre, octubre y noviembre en concordancia con la mayor cantidad de especies en flor disponibles para las abejas.

\section{Variación estacional del origen floral}

Se observó mayor riqueza de taxa y variabilidad en la primavera, es decir entre los meses de septiembre a diciembre (Fig. 4), un menor número fue registrado durante el verano, desde la última semana de diciembre y hasta febrero (Fig. 5) disminuyendo 


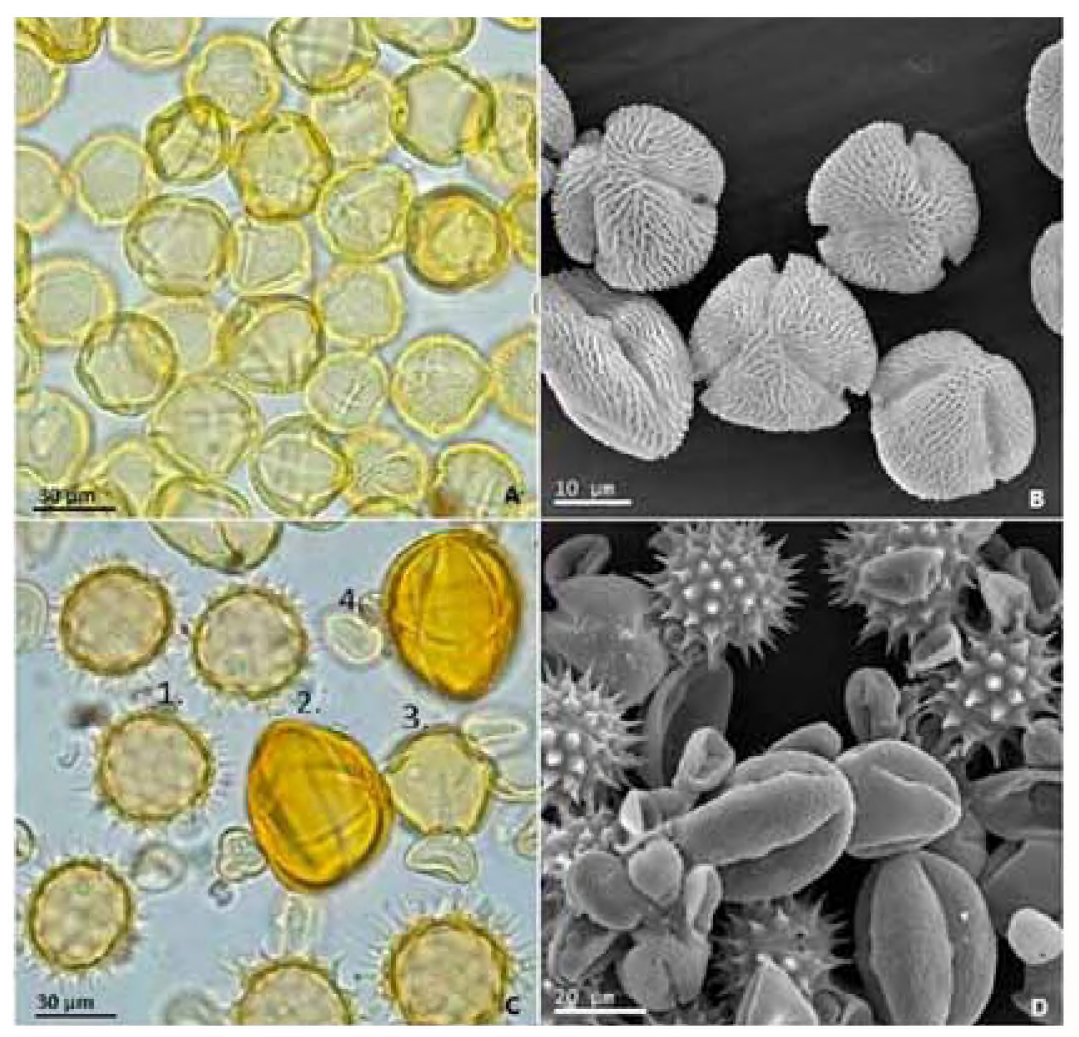

Lámina 2. Fotografías con microscopio óptico y electrónico de barrido de cargas procesadas por separado y en conjunto. A-B Submuestra14b: Schinopsis lorentzii. C-D. Muestra 9: mezcla de especies: 1. Helianthus annuus, 2. Sapium haematospermum, 3. Aloysia sp. y 4. Echium plantagineum.

Tabla 3. Registro polínico del acopio mensual realizado por las abejas. El asterisco indica las especies exóticas.

\begin{tabular}{|c|c|c|c|c|c|c|c|c|c|c|c|c|c|c|c|c|c|c|c|}
\hline \multirow{2}{*}{\multicolumn{2}{|c|}{$\begin{array}{l}\text { Estaciones } \\
\text { Meses }\end{array}$}} & \multicolumn{14}{|c|}{ PRIMAVERA } & \multirow{2}{*}{\multicolumn{2}{|c|}{$\begin{array}{l}\text { VERANO } \\
\text { FEBRERO }\end{array}$}} & \multicolumn{2}{|c|}{ OTOÑO } \\
\hline & & \multicolumn{3}{|c|}{ SEPTIEMBRE } & \multicolumn{4}{|c|}{ OCTUBRE } & \multicolumn{4}{|c|}{ NOVIEMBRE } & \multicolumn{3}{|c|}{ DICIEMBRE } & & & \multirow{2}{*}{\begin{tabular}{|l|} 
MAR \\
M17 \\
\end{tabular}} & \multirow{2}{*}{\begin{tabular}{|l|}
$A B R$ \\
$M 18$ \\
\end{tabular}} \\
\hline Familia & Especie & M1 & $\mathrm{M} 2$ & M3 & M4 & M5 & M6 & M7 & M8 & M9 & M10 & M11 & M12 & M13 & M14 & M15 & M16 & & \\
\hline Achatocarpaceae & Achatocarpus praecox & & & & $x$ & & & & & & & & & & & & & & \\
\hline \multirow[t]{2}{*}{ Anacardiaceae } & Shinus molle & & & & & & & & & & & & & & & & $x$ & & \\
\hline & Schinopsis lorentzii & & & & & & & & & & & & $x$ & $x$ & $x$ & $\mathrm{x}$ & $x$ & $\mathrm{x}$ & $x$ \\
\hline \multirow[t]{5}{*}{ Asteraceae } & Taraxacum sp. & & $x$ & $x$ & & & & & & & & & & & & & & & \\
\hline & Helianthus annuus* & $x$ & & $x$ & & & $x$ & $\mathrm{x}$ & $x$ & $x$ & $\mathrm{x}$ & & & $x$ & $x$ & & & & \\
\hline & Senecio grisebachii & & & & $x$ & $x$ & & & & & $x$ & & & & & & & & \\
\hline & tipo Baccharis - Eupatorium & & & & & & $\mathrm{x}$ & & & $x$ & $x$ & $x$ & & $\mathrm{x}$ & & $\mathrm{x}$ & & & $\mathrm{x}$ \\
\hline & tipo Verbesia & & & & & & & & & & & $x$ & $x$ & & & & $x$ & & \\
\hline Boraginaceae & Echium plantagineum ${ }^{*}$ & & $x$ & & $x$ & $x$ & $x$ & $x$ & & & $x$ & & & & & & & & \\
\hline Brassicaceae & Brassica napus* & $x$ & & & $x$ & $x$ & $x$ & $x$ & & $x$ & & & & & & & & & \\
\hline Cactaceae & Opuntia quimilo & & & & $x$ & & $x$ & $x$ & & & & & & & & & & & \\
\hline Cannabaceae & Celtis tala & & & & & & & & $\mathrm{x}$ & & & & & & & & & & \\
\hline Capparidaceae & Cynophalla retusa & & & & & & & & & & & & & & $x$ & & & & \\
\hline \multirow{7}{*}{ Fabaceae } & Acacia aroma & & & $x$ & $x$ & $x$ & & & & & & & & & & & & & \\
\hline & Erythrina crista-galli & & $x$ & & & & & & & & & & & & & & & & \\
\hline & Gleditzia amorphoides & & & $x$ & & & & & & & & & & & & & & & \\
\hline & Glycine max ${ }^{*}$ & & & & & & & & & & & & & & & $x$ & $x$ & & \\
\hline & Prosopis alba & $x$ & $\mathrm{x}$ & & & & & $\mathrm{x}$ & $\mathrm{x}$ & & & & & $\mathrm{x}$ & & & & & \\
\hline & Prosopis sp. & & & & $x$ & & & & & & & & & & & & & & \\
\hline & Prosopis ruscifolia & $x$ & & & & & & & & & & & & & & & & & \\
\hline \multirow[t]{2}{*}{ Euphorbiaceae } & Sapium haematospermum & & & & $x$ & $x$ & $x$ & $x$ & $x$ & & & & & & & & & & \\
\hline & Crotonsp. & & & & & & $x$ & & & $x$ & $x$ & $\mathrm{x}$ & & $x$ & & $x$ & $x$ & & \\
\hline Malvaceae & Sphaeralcea bonariensis & $x$ & $x$ & $\mathrm{x}$ & $x$ & $x$ & $x$ & & & & $x$ & & $x$ & & & $x$ & & & \\
\hline Meliaceae & Melia azedarach* & $x$ & & $x$ & & & & & & & & & & & & & & & \\
\hline Nyctaginaceae & Pisonia zapallo & & $\mathrm{x}$ & & & & & & & & & & & & & & $x$ & & \\
\hline Polygonaceae & Polygonum hydropiperoides & & & & & & & & & & & & $\mathrm{x}$ & & & & $x$ & & \\
\hline Poaceae & Zea mays* & & & & & & & & & & & & & $x$ & & & & & \\
\hline Rubiaceae & Borreria verticillata & & & & $\mathrm{x}$ & & & & & & $\mathrm{x}$ & $x$ & $\mathrm{x}$ & $x$ & & & & $\mathrm{x}$ & \\
\hline Rutaceae & \begin{tabular}{|l|} 
Citrus sp. ${ }^{*}$ \\
\end{tabular} & $x$ & & & & & & & & & & & & & & & & & \\
\hline Indet. 3c & & & & $\mathrm{x}$ & & & & & & & & & & & & & & & \\
\hline \multicolumn{2}{|c|}{ Total de tipos polínicos por muestra } & 7 & 6 & 7 & 10 & 6 & 8 & 6 & 4 & 5 & 8 & 5 & 5 & 7 & 3 & 5 & 7 & 2 & 3 \\
\hline
\end{tabular}


hacia el otoño, en el mes de marzo y abril (Fig. 6). A pesar de que la zona de muestreo se caracteriza por la presencia de cultivos extensivos como girasol y soja, las preferencias polínicas de las abejas mostraron un amplio abanico de opciones, especialmente de especies nativas. Esto permite poner en valor la posibilidad de adecuar los terrenos para permitir a las especies nativas su crecimiento y de esa manera proveer de polen a las abejas.

Las variaciones estacionales del recurso polínico están dadas por el número de especies en flor y los requerimientos proteicos de la colmena para alimentar a las crías (larvas). El recurso disponible disminuye hacia el otoño, en coincidencia con la disminución de la población de abejas en desarrollo dentro de la colmena (Fig. 6)

En la zona de estudio durante los meses de enero y febrero, se registran los más altos valores de temperatura, humedad y precipitaciones, condiciones inapropiadas para que las abejas realicen la actividad de forrajeo. Esta condición podría estar afectando la diversidad de especies colectadas por las abejas (Fig. 5).

\section{Contenido proteico de algunas especies}

Se seleccionaron 13 especies con frecuencia de aparición alta - Dominante y Secundario - en las muestras de cargas corbiculares. Los resultados obtenidos se resumen en la Tabla 4.

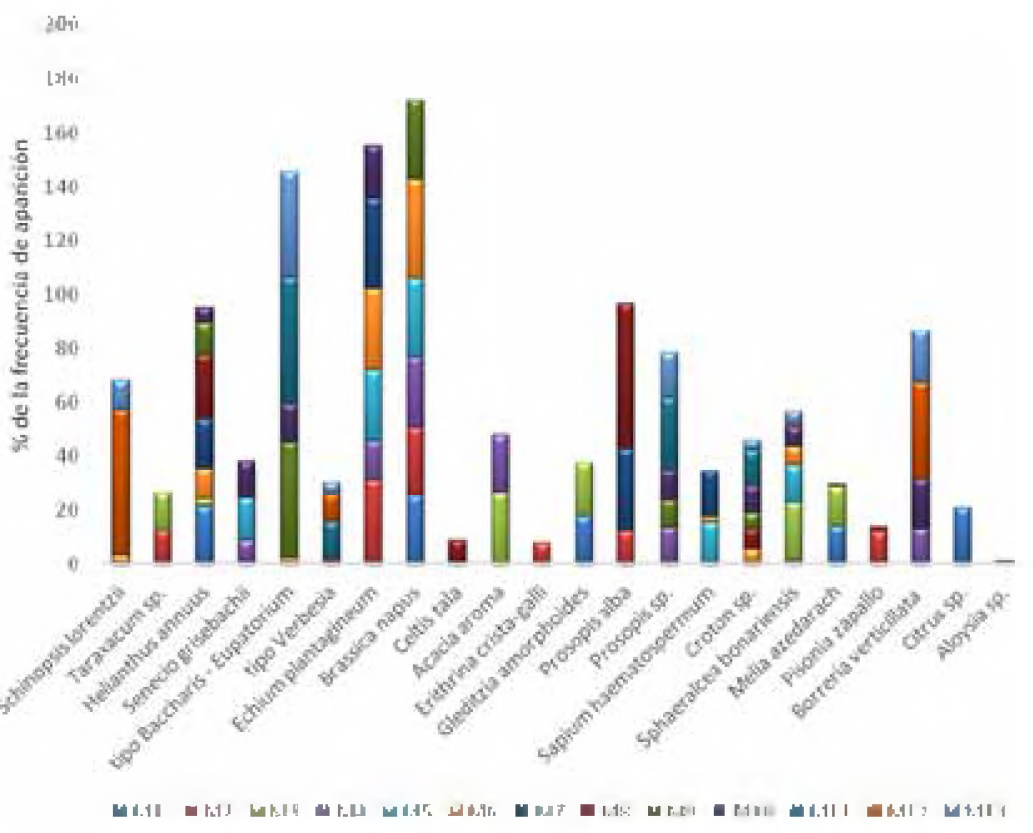

Figura 4. Representación de los distintos taxa en cada muestra recolectada desde el mes de septiembre hasta diciembre (estación= Primavera).

\section{Análisis estadístico multivariante}

6.1. Análisis de componentes principales.

El PCA realizado mostró una clara separación de las muestras de acuerdo a su origen botánico. La primer componente extraída (CP1) explicó el 33\% de la varianza total y se correlacionó negativamente de manera muy significativa con la abundancia relativa del tipo Baccharis-Eupatorium (n/v chilca), separando las muestras en el Grupo A con dominancia de este tipo polínico (muestras 9, 11, 13,15 y 18). La segunda componente (CP2) explicó el 25\% de la varianza total y separó las muestras con dominancia del polen de Schinopsis lorentzii (n/v quebra-

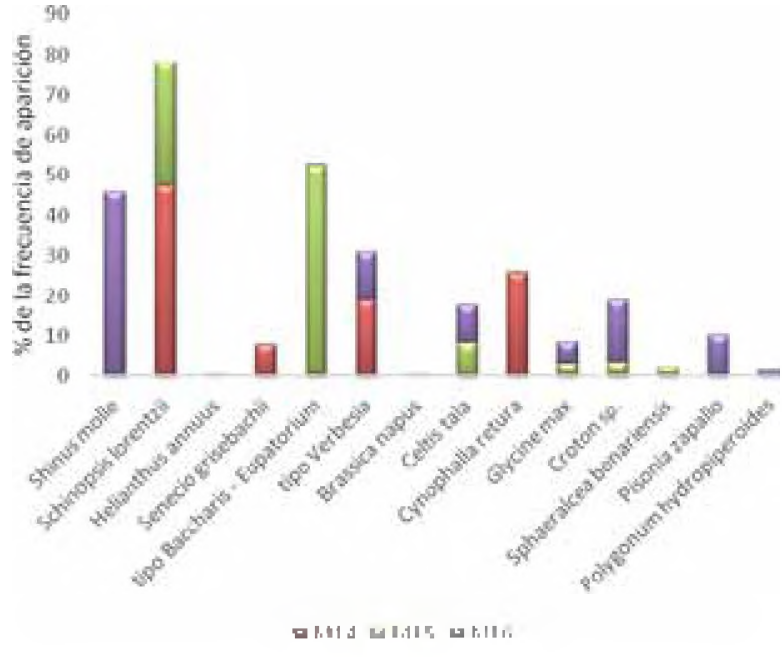

Figura 5. Representación de los distintos taxa en cada muestra recolectada desde el mes de diciembre hasta febrero (estación= Verano).

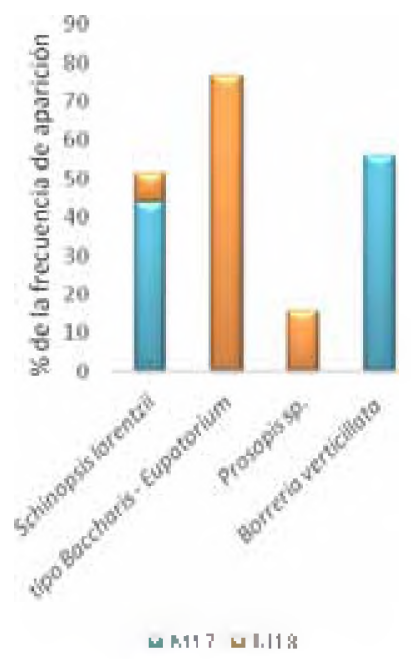

Figura 6. Representación de los distintos taxa en cada muestra recolectada desde el mes de marzo y abril (estación= Otoño). 
Tabla 4. Contenido de nitrógeno y porcentaje de proteína total en cargas corbiculares de origen floral conocido. Las filas sombreadas indican las especies con mayor porcentaje de proteína bruta registrada en el estudio.

\begin{tabular}{lllll}
\hline Familia vegetal & Nombre cientifico & Nombre común & N (\%) & Proteína total (\%) \\
\hline \multirow{4}{*}{ Asteraceae } & Helianthus annuus & Girasol & 2.910 & 18,19 \\
\cline { 2 - 5 } & Senecio grisebachii & Primavera & 3.823 & 23,89 \\
\cline { 2 - 5 } & Tipo Baccharis-Eupatorium & Chilca & 2.485 & 15,53 \\
\hline Anacardiaceae & Schinopsis lorentzii & Quebracho colorado & 4.105 & 25,65 \\
\hline Boraginaceae & Echium plantagineum & Flor morada & 4.970 & 29,38 \\
\hline Brassicaceae & Brassica napus & Colza & 2.644 & 16,53 \\
\hline Cactaceae & Opuntia quimilo & Quimil & 2.405 & 15,03 \\
\hline Euphorbiaceae & Sapium haematospermum & Curupí & 5.675 & 35,47 \\
\hline \multirow{3}{*}{ Fabaceae } & Acacia aroma & Aromito & 3.820 & 23,88 \\
\cline { 2 - 5 } & Gleditzia amorphoides & Espina corona & 2.806 & 17,54 \\
\cline { 2 - 5 } & Prosopis alba & Algarrobo & 3.331 & 20,81 \\
\hline Malvaceae & Sphaeralcea bonariensis & Malva & 3.117 & 19,48 \\
\hline
\end{tabular}

cho colorado) y Borreria verticillata formando el Grupo B (muestras 12, 14 y 17) hacia el lado negativo del eje. Las restantes muestras se agruparon en el Grupo $\mathrm{C}$ en el cuadrante positivo de ambos ejes sin una clara dominancia de ningún tipo polínico (Fig. 7).

6.2. Análisis de Agrupamiento. En el dendrograma obtenido con el análisis de agrupamiento realizado pudo observarse la conformación de dos Grupos bien definidos, uno con las muestras de septiembre y octu-

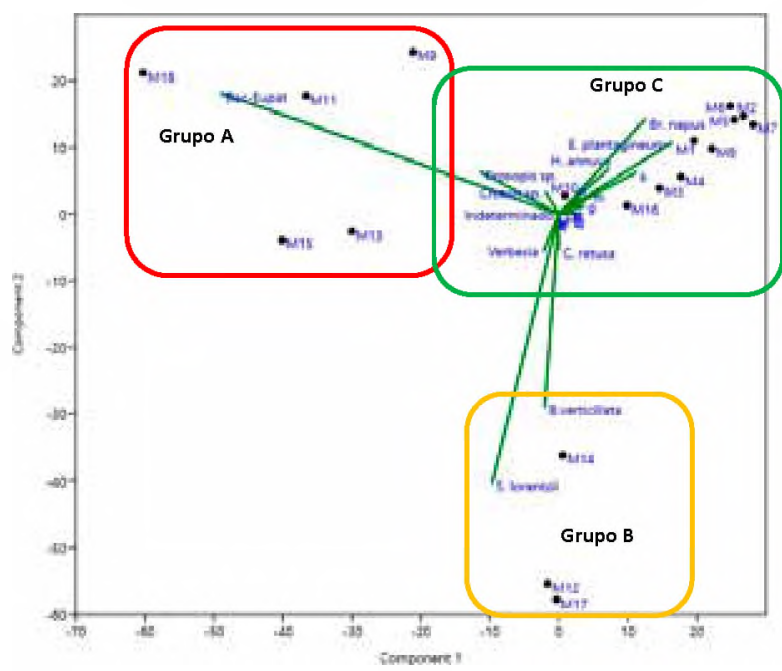

Figura 7. Biplot elaborado con las dos componentes extraídas del Análisis de Componentes Principales, se observa el agrupamiento de las muestras de acuerdo a su origen botánico.

Referencias: a. Achatocarpus praecox, b. Schinus molle, c. Taraxacum sp., d. Senecio grisebachii, e. Opuntia quimilo, f. Celtis tala, g. Acacia aroma, h. Erythrina crista-galli, i. Gleditzia amorphoides, j. Glycine max, k. Prosopis alba, 1 . Prosopis ruscifolia, $\mathrm{m}$. Sapium haematospermum, n. Sphaeralcea bonariensis, o. Melia azedarach, p. Pisonia zapallo, q. Polygonum hydropiperoides, r. Zea mays, s. Citrus sp., t. Aloysia sp. bre (muestras 1 a 7) y el otro con las muestras de los restantes meses muestreados, reflejando los cambios temporales en la oferta floral que disponen las abejas en el sitio analizado (Fig. 8). La línea de corte se estableció teniendo en cuenta la composición polínica de las muestras que forman los dos grupos y que reflejan las especies en flor determinando las diferencias temporales en cuanto a la oferta polínica de primavera (Grupo 2) y verano (Grupo 1). En primavera el principal recurso forrajeado por las abejas fue $\mathrm{He}$ lianthus annuus y Brassica napus, especies exóticas explotadas como cultivos extensivos. En tanto que, en verano la principal fuente de proteína la aportaron los quebrachales y chilcales, constituidos principalmente por Schinopsis lorentzii (quebracho colorado) y tipo Baccharis-Eupatorium (chilca).

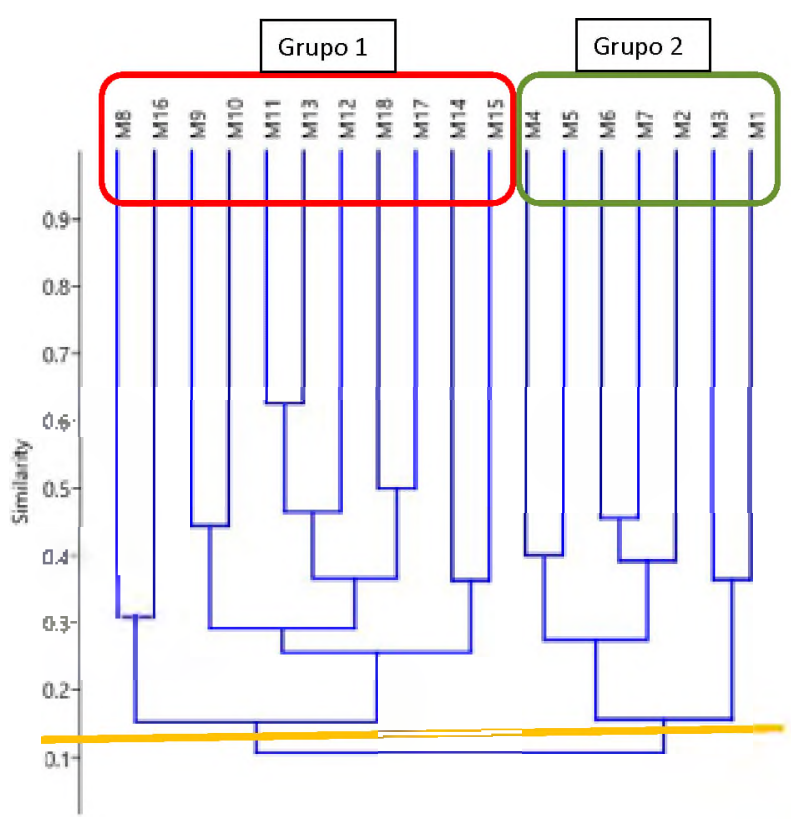

Figura 8: Dendrograma obtenido por el análisis de agrupamiento realizado. 


\section{DISCUSIÓN}

La metodología de muestreo y análisis de las cargas corbiculares fue realizada teniendo en cuenta los objetivos particulares y generales propuestos en el presente trabajo. Los autores consultados con los cuales se contrasta los resultados obtenidos, han realizado distintos procedimientos que pueden ser comparados en mayor o menor medida. Sin embargo, todos los autores coinciden en la formulación de los objetivos del estudio, que son predominantemente similares. En todos los casos se busca conocer las preferencias y el grado de aprovechamiento, por parte de las abejas, de la flora disponible.

El conocimiento del origen floral de las cargas corbiculares y su contenido proteico, tanto como su variación estacional constituye una valiosa herramienta para el desarrollo apícola. El análisis de las cargas corbiculares revela la flora que seleccionan las abejas en una región permitiendo la evaluación de la contribución proteica de cada taxón (Louveaux, 1958).

\section{El color como indicador del origen botánico}

El color de las cargas polínicas es variable, el más frecuente es el amarillo, pero los hay azules, rojos, castaños, verdes y hasta negros como en la amapola (Ortega Sada, 1987). En el presente trabajo se registraron mayormente cargas de color amarillo en distintos tonos, desde amarillo muy claro (citrus) hasta amarillo intenso (maíz, quebracho colorado), anaranjado (girasol), distintos tonos de castaño desde beige (Borreria vertiillata, Indeterminado $3 b$, espina corona) hasta marrón oscuro (primavera), verde (ceibo) y lila (flor morada). El color es un buen indicador para identificar el origen botánico en algunas cargas corbiculares en las cuales se observó relación directa, por ejemplo Schinopsis lorentzii, Helianthus annuus, Echium plantagineum, Erythrina crista-galli, Zea mays, y Opuntia quimilo (Tabla 2). Sin embargo, para la determinación de otras especies, el color es una variable débil ya que más de una especie diferente puede coincidir en el tono del color. Cuando esto ocurre, hay autores que recurren a otro criterio para separar las cargas por ejemplo: textura y forma (Faye et al. 2002).

Las cargas mixtas son fácilmente reconocibles en las trampas por la presencia de al menos dos colores diferentes. Esto probablemente indica deficiencia del recurso, sin embargo cuando las cargas son visiblemente uniformes respecto al color es un indicador de la "constancia floral" (Free, 1963; Free y Willians, 1974).

\section{Origen botánico y geográfico de las cargas corbiculares del Chaco Seco}

El presente trabajo muestra una importante riqueza de especies (31 taxa) y una interesante diver- sidad de familias botánicas (18) utilizadas por Apis mellifera $\mathrm{L}$. como recurso polinífero para alimentar a las crías. En mayor o menor medida esta riqueza fue registrada por otros autores como así también la alta representación de especies de Fabaceas y Asteraceas (e.g. Faye et al., 2002; Forcone, 2002, Forcone et al., 2011; Tamame 2011; Tellería, 1993). En tercer lugar de importancia, sumadas a las Fabaceae y Asteraceae, Forcone et al. (2011) registraron Rosáceas y Andrada y Tellería (2005) registraron Poaceas con valor apícola.

El área de muestreo corresponde a una zona intensamente agrícola, existen grandes extensiones de cultivares de girasol, soja, colza y maíz, en los que se registra actividad de pecoreo por parte de las abejas y se refleja en la presencia de cargas corbiculares de esas especies durante varios meses del muestreo (Tabla 3). Sin embargo es evidente la predominancia de especies nativas sobre las exóticas en las preferencias alimenticias de las abejas, ya que muestran mayor número de especies nativas, especialmente en la estación primaveral (Fig. 3). El análisis del origen floral de las cargas de polen recolectadas en General Pinedo, reveló que el comportamiento forrajero de Apis mellifera es similar al observado en la región Centro y Pampeana, en donde muchos de los taxones pecoreados son malezas comunes en los monocultivos (Andrada y Tellería 2005; Faye et al., 2002). Sin embargo, en la región Patagonia, los taxa predominantes son los exóticos sobre los nativos (Forcone et al., 2011).

En la región Chaqueña el aporte de polen provino de especies arbóreas y arbustivas, en tanto que las más frecuentes en las muestras provinieron de plantas herbáceas de especies cultivadas (girasol y colza) y malezas introducidas (eg. flor morada) y nativas (eg. malva)

Un dato novedoso registrado por Forcone et al. (2011) fue la presencia de cargas de esporas de hongos en el mes de Febrero. Existen referencias que afirman que las abejas colectan cualquier producto que tenga aspecto pulverulento similar al polen, por ejemplo aserrín (Louveaux, 1958), polvo de carbón (Roulston y Cane, 2000) y esporas de hongos (Andrada y Tellería, 2005; Forcone et al., 2011 y Percival, 1955).

Las cargas corbiculares del Chaco son típicamente monoespecificas. Sin embargo, en la región Pampeana, Tamame (2011) registró la presencia de cargas mixtas que podría deberse a reducción del recurso de la floración, de la competencia con otros polinizadores o factores meteorológicos.

Forcone et al. (2011) encontraron que la mayor contribución de polen a las colmenas provino de malezas asociadas a los cultivos, principalmente Brassicaceae y Convolvulus arvensis.

El origen geográfico del polen comercial puede ser determinado mediante los estudios polínicos. Los taxa presentes en distintas áreas estudiadas reflejan 
Tabla 5. Contenido de proteína total de algunas especies colectadas por las abejas en diferentes regiones de Argentina. La columna sombreada indica los resultados obtenidos en el presente estudio.

\begin{tabular}{|c|c|c|c|c|c|c|}
\hline \multicolumn{2}{|c|}{$\begin{array}{c}\text { Ecorregiones } \\
\text { (Morello et al. 2012) }\end{array}$} & Espinal & $\begin{array}{c}\text { Monte de } \\
\text { Llanuras y } \\
\text { Mesetas }\end{array}$ & $\begin{array}{c}\text { Estepa } \\
\text { Patagónica }\end{array}$ & \multicolumn{2}{c|}{ Chaco Seco } \\
\hline \multicolumn{2}{|c|}{ Provincia } & La Pampa & La Pampa & Santa Cruz & \multicolumn{2}{c|}{ Chaco } \\
\hline $\begin{array}{c}\text { Familia vegetal } \\
\text { Nombre cientifico }\end{array}$ & $\begin{array}{c}\text { Nombre } \\
\text { común }\end{array}$ & $\begin{array}{c}\text { Andrada y } \\
\text { Tellería 2005 }\end{array}$ & Tamame 2011 & $\begin{array}{c}\text { Forcone et al. } \\
2011\end{array}$ & \multicolumn{2}{c|}{ Changazzo 2019} \\
\hline $\begin{array}{c}\text { Asteraceae } \\
\text { Baccharis sp. }\end{array}$ & Chilca & & 11,6 & & $\begin{array}{c}\text { Tipo Baccharis- } \\
\text { Eupatorium }\end{array}$ & 15,53 \\
\hline $\begin{array}{c}\text { Senecio sp. } \\
\text { Brassicaceae } \\
\text { Brassica sp. }\end{array}$ & Primavera & 15.5 & 18,9 & 16.8 & S. grisebachii & 23,89 \\
\hline $\begin{array}{c}\text { Cactaceae } \\
\text { Opuntia sp. }\end{array}$ & Quimil & 30.5 & 36,1 & 21.25 & B. napus & 16,53 \\
\hline
\end{tabular}

la región fitogeográfica en la que se realizaron los muestreos. Algunos taxa registrados en las muestras de Gral. Pinedo indican claramente que la procedencia de las muestras corresponde a la región fitogeográfica Chaqueña, en el área de transición entre el Chaco Seco y el Chaco Húmedo. Los indicadores más relevantes son: Schinopsis lorentzii, Opuntia quimilo, Cynophalla retusa, Gleditzia amorphoides y Pisonia zapallo.

\section{El valor proteico del polen y su origen floral}

El polen varía desde 8 a $40 \%$ respecto de su contenido proteico (Maurizio, 1959) las especies anemófilas son las menos ricas en proteína respecto de los frutales y leguminosas (Ortega Sada, 1987). Los requerimientos proteicos óptimos para el desarrollo de las crías de Apis mellifera se encuentran en un rango de 23 a $30 \%$ de proteína cruda (Herbert y Shimanuki, 1978).

El valor nutritivo del polen depende en gran medida del porcentaje de proteína, que las abejas seleccionan aquellas especies vegetales que ofrecen polen con elevado contenido de nitrógeno (Louveaux, 1958; Jean-Prost, 1989), condición que se cumple en las plantas de polinización entomófila (Stanley y Linskens, 1974). Kleinschmidt y Kondos (1976) concluyeron que el polen con menos de $20 \%$ de proteína cruda no puede satisfacer las necesidades de la colonia. El óptimo se encuentra por encima del 23\% (Shaw, 1999). Por cada 10 gramos de proteína requerida es necesario que consuma 48 gramos de polen que contiene $30 \%$ de proteína cruda. Si el contenido de proteínas del polen se reduce del $30 \%$ al $20 \%$, la colonia aumenta el consumo de polen de 48 gramos a 72 gramos en un intento de cubrir sus requerimientos. Es decir, si una colonia consume polen de baja calidad aumenta el consumo para compensar el déficit (Kleinschmidt y Kondos, 1976).
Andrada y Tellería (2005), en la provincia fitogeográfica del Espinal, observaron que durante la primavera las plantas nativas del género Prosopis se recolectaron más intensamente y el polen posee alto nivel de proteína. Por otra parte, notaron que en días fríos y ventosos el polen recolectado fue escaso, vale decir que la temperatura y el viento afectaron la actividad de alimentación de las abejas.

En la Región Patagónica, los estudios de Forcone et al. (2011) mostraron que las plantas leñosas fueron la principal fuente de polen al final del invierno y principios de primavera (septiembre-octubre), sin embargo el polen de los arboles registró el menor porcentaje de proteína cruda. Hacia el final de la primavera y durante el verano, el flujo de polen a las colmenas provino principalmente de plantas herbáceas, en las cuales se registraron los mayores valores en porcentaje de proteína cruda (desde $20 \%$ en una maleza como Convolvulus arvensis hasta varias Leguminosas, como por ejemplo 26,3\% en Adesmia sp.).

Las especies activamente utilizadas por las abejas, registradas en los rangos de frecuencia Dominante [D] y Secundario [S] representan el mayor volumen de polen utilizado, aportando la mayor cantidad de proteína. Sin embargo las especies registradas en los rangos de menor importancia [M] y en traza [T], contribuyen minoritariamente pero al mismo tiempo aportan variabilidad en cuanto a los nutrientes del polen. En este sentido, el consumo de diferentes tipos de polen tiene la ventaja de dar una dieta más equilibrada, pues cada tipo polínico posee una composición nutricional particular (Schmidt, 1984).

A partir del análisis del contenido proteico del polen de algunas especies colectadas por las abejas de la región estudiada, fue posible compararlos con los registros de otros autores para diferentes regiones de nuestro país (Tabla 5). Es interesante ver que el mismo recurso puede comportarse de diferente manera 
en distintas regiones del país, como se puede observar en la Tabla 5 alg unas especies muestran el mismo porcentaje de proteína total o con leves variaciones en algunas regiones, por ejemplo Senecio registra valores similares en el Centro y Sur del país $(15,5$ a $16,8 \%$ ), en tanto que en la región estudiada registró valores altos $(23,89 \%)$. En tanto que otras especies con valores significativamente diferentes, por ejemplo Brassica sp. presenta valores más elevados en el Espinal y Monte (más del $30 \%$ ), valores más bajos en la Estepa Patagónica $(21,25 \%)$ hasta muy bajos $(16,53 \%)$ en el Chaco Seco. Por otra parte, especies como Opuntia quimilo no mostraron diferencias significativas respecto de la ecorregión estudiada.

Las variaciones respecto del contenido proteico total podrían deberse a las condiciones químicas y físicas del suelo en el que crecen las plantas. Posiblemente, en suelos con niveles óptimos de nutrientes y considerados aptos para la agricultura, los niveles de proteína presenten en el polen sean mayores. Sin embargo, valores registrados para algunas especies nativas indican porcentajes menores de proteína en suelos ricos y aptos para la agricultura como se puede ver en la Tabla 5 (eg. Senecio sp.).

Los valores de proteína total obtenidos en muestras de Chaco para Helianthus annuus $(18,19 \%)$ son bajos y similares a los citados por otros autores, Nicolson y Human (2012) hallaron $14,21 \%$ en muestras de Francia, en tanto que Somerville y Nicol (2006) citan valores de 13,8 y $12,9 \%$ para muestras de Australia. El polen de girasol, especie comúnmente cultivada en la región, posee niveles de proteína cruda muy pobres (Manning, 2001), lo que se ve reflejado en la reducción de la vida de las pecoreadoras. Si una colonia de abejas obtiene la mayor parte del polen en un cultivo de girasol, es esperable una disminución en la población debido a los niveles de proteína deficientes en el cuerpo de las abejas adultas.

El porcentaje de proteína del polen de Echium plantagineum en Chaco alcanzó el 29,38\%, valores más altos llegando a $32,8 \%$ fueron registrados por Somerville y Nicol (2006).

En el presente estudio se analizó el contenido proteico de especies nativas, las cuales mostraron niveles interesantes de proteína total: Euphorbiaceae: $35,47 \%$ en Sapium haematospermum (curupí). Fabaceae: $23,88 \%$ en Acacia aroma (aromito), $17,54 \%$ en Gleditzia amorphoides (espina corona). Malvaceae: $19,48 \%$ en Sphaeralcea bonariensis (malva) y en un tipo de polen Indeterminado se registró $20,86 \%$ de proteína total.

Forcone et al. (2011) obtuvieron un rango de $12,47 \%$ a $26,3 \%$ de proteína cruda en muestras de polen corbicular en la región Estepa Patagónica (Santa Cruz). Andrada y Tellería (2005) mencionan un rango de 13,6 a 31,9\% para la región del Espinal (La
Pampa). Por otro lado, Tamame (2011) describe un rango más amplio desde 11,6 a 36,1\% en la región del Monte (La Pampa). En este trabajo el rango obtenido para la región Chaco Seco fue de 15,03 a 35,47\% de proteína total, superando los valores mínimos de otras regiones y alcanzando los niveles máximos similares registrados.

Los valores de proteína más altos (mayores a 20\%) fueron registrados en especies de las familias: Asteraceae (primavera), Boraginaceae, Euforbiaceae y Fabaceae (aromito), coincidiendo con la estación primaveral en la cual hay mayores requerimientos de proteína para el desarrollo de las larvas y con ello el crecimiento de la colonia. En tanto que los valores más bajos (menores a 20\%) provinieron de especies de las familias: Asteraceae (chilca y girasol), Brassicaceae, Cactaceae, Fabaceae (espina corona) y Malvaceae, este aporte corresponde en gran parte al final del periodo de primavera e inicio del verano, momento en el que puede registrarse un bache en la oferta de floración. Las especies analizadas en el presente estudio muestran que el $45 \%$ de los taxa aporta niveles de proteína mayores al $20 \%$ y el $55 \%$, si bien aporta niveles menores al $20 \%$ puede considerarse que contribuyen a que las abejas dispongan de diversidad de nutrientes para tener una dieta equilibrada.

\section{CONCLUSIONES}

El estudio de las cargas polínicas recolectadas por Apis mellifera L. en la localidad de General Pinedo -provincia del Chaco- durante el periodo 2014-2015, reveló las preferencias alimentarias de las abejas. Las conclusiones arribadas a partir del presente estudio pueden sintetizarse en los siguientes enunciados:

- La riqueza estuvo representada por 31 taxa, de los cuales se identificaron 23 a nivel específico, 5 a nivel genérico, 2 a tipo polínico y 1 no pudo ser determinado taxonómicamente.

Las familias vegetales identificadas fueron 18 , lo que muestra una amplia actividad de forrajeo por parte de las abejas. Las Fabaceae y Asteraceae fueron las mejor representadas en número de especies, en coincidencia con otras regiones fitogeográficas del país.

El $81 \%$ son especies nativas y el $19 \%$ son exóticas, el polen dominante [D] registrado, perteneció a especies nativas y el secundario [S] a especies nativas y cultivadaslo que indica las preferencias polínicas de las abejas, incluso en una zona que se caracteriza por la presencia de cultivos extensivos (principalmente girasol y soja). Esto permite poner en valor la posibilidad de adecuar los terrenos para permitir a las especies nativas su crecimiento y de esa manera proveer de polen a las abejas.

El color de las cargas mostró relación directa con el origen botánico en once (11) especies: Borreria verticillata, Citrus sp., Echium plantagineum, 
Erythrina crista-galli, Helianthus annuus, Indeterminado, Opuntia quimilo, Sapium haematospermum, Schinopsis lorentzii, Taraxacum sp., Zea mays, sin embargo esta varíale mostró limitaciones como indicador de origen floral para otras especies (Acacia aroma, Brassica napus, tipo Baccharis-Eupatoium, tipo Croton, Gleditzia amorphoides, Prosopis alba y Prosopis ruscifolia).

- La riqueza de especies registradas fue mayor en PRIMAVERA (22 taxa) que en VERANO (14 taxa) decayendo notablemente en el OTOÑO (4 taxa). Esto puede estar relacionado con los diferentes requerimientos de la colmena, ya que en otoño e invierno se reduce la postura la reina.

- Varias especies identificadas en este trabajo constituyen nuevos registros como recurso polinífero para la flora apícola de Argentina, ellos son: Acacia aroma, Achatocarpus praecox, Aloysia sp., Borreria verticillata, Citrus sp.*, Croton sp., Cynophalla retusa, Echium plantagineum*, Erythrina crista-galli, Gleditzia amorphoides, Glycine max*, Prosopis alba, Prosopis ruscifolia, Pisonia zapallo, Polygonum hydropiperoides, Sapium haematospermum, Schinopsis lorentzii yMelia azedarach*.

- Algunos taxa fueron enunciados por otros autores a nivel de especie: Celtis tala, Helianthus annuus y Zea mays. Además, a nivel genérico también han sido mencionados, sin embargo se trata de especies diferentes: Brassica napus*, Baccharis sp., Schinus molle, Senecio grisebachii, Opuntia quimilo, Sphaeralcea bonariensisytipo Verbesina.

- El análisis de componentes principales mostró 3 Grupos claramente diferenciables por el origen floral de las 18 muestras: Grupo A caracterizado por la presencia de polen del tipo-Baccharis-Eupatorium, Grupo B por Schinopsis lorentzii y Borreria verticillata, en tanto que el Grupo C mostró la presencia de varias especies sin predominancia de ninguna. EL análisis de agrupamiento separó las muestras en 2 grupos claramente definidos: Grupo 1 de septiembre a octubre (Muestras 1 al 7) y Grupo 2 de noviembre a abril (Muestras 8 al 18) indicando su distribución temporal.

- Los estudios de contenido proteico de las cargas corbiculares realizados en este trabajo aportan información acerca de la capacidad nutricional de las especies nativas: Acacia aroma $(23,88 \%)$, Gleditzia amorphoides (17,54\%), Senecio grisebachii (23,89\%), Sphaeralcea bonariensis (19,48\%), Tipo Baccharis-Eupatorium(15,53\%), Opuntia quimilo (15,03\%), Prosopis alba (20,81\%), Sapium haematospermum $(35,47 \%)$, Schinopsis lorentzii $(25,65 \%)$ y las exóticas cultivadas: Brassica napus (16,53\%), Echium plantagineum (29,38\%), Helianthus annuus $(18,19 \%)$ de nuestra región.

- Se citan por primera vez para Argentina los porcentajes de proteína total de cargas corbiculares de las siguientes especies: Acacia aroma, Echium plantagineum, Gleditzia amorphoides, Helianthus annuus, Prosopis alba, Sapium haematospermum, Schinopsis lorentzii, Sphaeralcea bonariensis y en un tipo de polen Indeterminado.

El rango de proteína total obtenido para la región Chaco Seco es de 15,03 a $35,47 \%$, superando los valores mínimos de otras regiones y alcanzando los niveles máximos similares registrados.

Los valores de proteína más altos (mayores a 20\%) fueron registrados en la estación primaveral en la cual hay mayores requerimientos de proteína para el desarrollo de las larvas. En tanto que los valores más bajos (menores a $20 \%$ ) corresponde en gran parte al final del periodo de primavera e inicio del verano, momento en el que puede registrarse un bache en la oferta de floración.

- El 54\% de los 13 taxa analizados muestran que el aporta de proteína es mayor al $20 \%$ y el $46 \%$ de los taxa, si bien aporta niveles menores al $20 \%$ puede considerarse que contribuyen a una dieta equilibrada para que las abejas dispongan de diversidad de nutrientes.

La abeja melífera vive en estrecha relación con la vegetación circundante, de la que obtiene néctar y el polen para su alimentación. Esta relación insectoplanta es interesante de conocer, por cuanto nos revela las preferencias alimenticias de la abeja. Así, conociendo al mismo tiempo la vegetación de una zona, podremos valorar el aprovechamiento apícola de un territorio, tanto para la obtención de determinados productos, como para la polinización de cultivos.

Por otra parte, el conocimiento del valor nutricional que aporta el polen de las especies de plantas nativas de nuestra región y que circundan los apiarios, permitirá realizar un mejor manejo del apiario por parte del productor para obtener mayores rendimientos en la producción apícola. Vale decir que mediante el conocimiento de la flora apícola y su aporte proteico será factible realizar predicciones para el manejo sustentable de la Apicultura.

En base a los resultados de este estudio inicial y por ser el primero para la Región del Chaco Seco, los aspectos de mejoras para la zona que podrían tenerse en cuenta son:

- En cuanto a la VEGETACIÓN y atendiendo a las preferencias alimentarias de las abejas registradas en este trabajo, ( $81 \%$ por las especies nativas sobre $19 \%$ de especies exóticas). Sería recomendable que los productores adecúen los terrenos para la recuperación de las comunidades naturales con especies nativas como por ej.: Prosopis alba y Schinopsis lorentzii que además de ser aprovechados por las abejas, tienen muchos usos y aplicaciones: alto valor maderable, aportan otros productos no madereros y también se los usa para leña y carbón. 
- Respecto a la NUTRICIÓN de las colmenas, sería recomendable realizar algún proceso o suministro de suplementación, cuando se produce algún "bache" de la producción de polen por parte de la vegetación. En este sentido, quizás ahí sería recomendable indicar a los productores que de acuerdo a la situación en la que se encuentran la colmena podría agregarse algún complemento dietario comercial ya que la naturaleza no está aportando el polen (proteína) necesario para el desarrollo de las larvas.

- Otro aspecto destacable, es la posibilidad de DIVERSIFICACIÓN de la producción apícola ya que además de producir miel, algunos apicultores se pueden dedicar a la producción de polen comercial.

Finalmente, a partir de los resultados obtenidos resulta interesante y necesario continuar con estudios de esta temática para conocer detalladamente las propiedades nutricionales del polen que disponen las abejas de esta región.

\section{Agradecimientos}

Los autores desean expresar su agradecimiento a la Facultad de Ciencias Agrarias de la UNNE, a la Cátedra de Morfología de Plantas Vasculares y al Laboratorio de Melisopalinología por brindar los insumos y poder utilizar las instalaciones para realizar el trabajo. A los productores de la Cooperativa Apícola Granjera "La Misky Shumaj" Limitada, especialmente al Sr. Hugo Iglesias por realizar la toma de muestras para llevar a cabo el estudio. Al Med. Vet. Luis Zago del INTA Sáenz Peña por aportar los recursos económicos para financiar el procesamiento y análisis de las muestras.

\section{BIBLIOGRAFÍA}

Aguirre Rollet, M.D. 2017. Autenticación de mieles monofloras de algarrobo y quebracho colorado, mediante estudios polínicos, sensoriales y físicos-químicos. Trabajo final para acceder al título de Ingeniero Agrónomo. Facultad de Ciencias Agrarias-UNNE. Directora: Cristina R. Salgado.

Andrada, A.C. 2003. Flora utilizada por Apis mellifera L. en el sur del Caldenal (Provincia Fitogeográfica del Espinal), Argentina. Revista del Museo Argentino de Ciencias Naturales 5(2): 329-336.

Andrada, A.; Valle, A.; Paolini, P.; Gallez, L. 2004. Pollen and nectar sources used by honeybee colonies pollinating sunflower (Helianthus annuus) in the Colorado river valley, Argentina. Boletin de la Sociedad Argentina de Botánica 39: 75-82.

Andrada, A.C., Tellería M.C. 2005. Pollen collected by honey bees (Apis mellifera L.) from south of Caldén district (Argentina): botanical origin and protein content. Grana 44: 115-122.
Basilio A.M. 2000. Cosecha de polen por Apis mellifera (Hymenoptera) en el bajo delta del Paraná: comportamiento de las abejas y diversidad del polen. Revista del Museo Argentino de Ciencias Naturales, n.s. 2: 111-121.

Cabrera M.M. 2006. Caracterización polínica de las mieles de la provincia de Formosa, Argentina. Revista del Museo Argentino de Ciencias Naturales 8(2): 135-142.

Chifa, C.; Montenegro, S.; Avallone, C.M.; Pire, S.M. 2000 Control de calidad de las Mieles de la Provincia del Chaco - Argentina y Mapa Apícola. Universidad Nacional del Nordeste, Facultad de Agroindustrias, Dpto. de Tecnología, Cátedra de Tecnología Industrial III. www. fai.unne.edu.ar

Cook, M.S.; Awmack, C.S.; Murrey, D.A.; Williams, I.H 2003. Are honey bees' foraging preferences affected by pollen amino acid composition? Ecol. Entomol. 28: 622627.

Dimou, M.; Tananaki, C.; Liolios, V.; Thrasyvoulou, A 2014. Pollen foraging by honey bees (Apis mellifera L.) in Greece: Botanical and geographical origin. J. Apic. Sci. 58: 11-23.

Erdtman, G. 1960. The acetolysis method. Svensk. Bot. Tidskr. 54: $561-564$.

Faye, P.F.; Planchuelo, A. M.; Molinelli, M.L. 2002. Relevamiento de la Flora apícola e identificación de cargas de polen en el Sureste de la provincia de Córdoba, Argentina. Agricientia 19: $19-30$.

Forcone, A. 2002. Bee - collected pollen in the lower Valley of the Chubut river (Argentina). Boletin de la Sociedad Argentina de Botánica 37: 251-259.

Forcone, A.; Aloisi, P.V.; Ruppel S.; Muñoz, M. 2011. Botanical composition and protein cont of pollen collected by Apis mellifera L. in the north-west of Santa Cruz (Argentinean Patagonia). Grana 50: 30-39.

Free, J B. 1963. The flower constancy of honeybees. Journal of Animal Ecology 32: 119-131.

Free, J B; Williams, I H. 1972. The transport of pollen on the body hair of honey- bees and bumblebees. Journal of Applied Ecology 9: 609-615.

Gurini, L.; Basilio, A.M. 1995. Flora Apícola en el Delta del Paraná. Darwiniana 33(1-4): 337-346.

Herbert Ew, J.R.; Shimanuki, H. 1978. Chemical composition and nutritive value of the bee collected and beestored pollen. Apidologie 9:33-40.

Jean-Prost, P. 1989. Apicultura. Ed. Mundi Prensa. Madrid $726 \mathrm{p}$.

Kleinschmidt, G.; Kondos, A. 1976. Influence of crude protein levels on colony production. The Australasian Beekeeper 78:36-39.

Louveaux, J. 1958. Recherches sur la récolte du pollen par les abeilles (Apis mellifera L.) Annal Abeille 4:197-221.

Louveaux, J.; Maurizio, A.; Vorwohl, G. 1978. Methods of melissopalynology. Bee World 51 (3): 125- 138.

Manning, R. 2001. Fatty acids in pollen: a review of their importance to honeybee. Bee World 82: 60-75. 
Markgraf, V.; D’Antoni, H.L. 1978. Pollen Flora of Argentina. The University of Arizona Press. Tucson. Arizona.

Maurizio, A. 1959. Factors influencing the lifespan of bees. Ciba Foundation Symposium: 231-243.

Maurizio, A.; Louveaux, J. 1965. Pollen de plantes melliféres d'Europe. Un. Group. Apicoles Français. Paris.

Morello, J.; Matteucci, S.; Rodriguez, A.; Silva, M. 2012. Ecorregiones y complejos ecosistémicos Argentinos. FADU GEPAMA, Editorial Orientación Gráfica Argentina. Buenos Aires. 719 p.

Naab, O.A.; Tamame, M.A. 2007. Flora apícola primaveral en la región del Monte de la provincia de La Pampa (Argentina). Boletín de la Sociedad Argentina de Botánica 42: 251-259.

Naab, O.A.; Ponce, A. 2001. Análisis del polen en mieles y cargas polínicas de Apis mellifera de la región del monte, provincia de La Pampa-Argentina. Anales XXVIII Jornadas Argentinas de Botánica, La Pampa, Argentina, pp. 141.

Nicolson, S.W; Human, H. 2012. Chemical composition of the 'low quality' pollen of sunflower (Helianthus annuus, Asteraceae). Apidologie 44:144-152. DOI: 10.1007/s13592-012-0166-5

Ortega Sada, J.L. 1987. Flora de interés apicola y polinización de cultivos. Ed. Mundipresa. España. 149 p.

Percival, M. 1955. The presentation of pollen in certain angiosperms and its collection by Apis mellifera L. New Phytologist 54: 353-368

Pire, S.M.; Anzotegui, L.M.; Cuadrado, G.A. (Eds.). 1992. Atlas palinológico del nordeste argentino, I: Fam. Amaranthaceae, Anacardiaceae, Apocynaceae, Araliaceae y Sapindaceae. D'Orbignyana 7: 1-75.

Pire, S.M.; Anzotegui, L.M.; Cuadrado, G.A.1994. Atlas palinológico del nordeste argentino, II: Fam. Aquifoliaceae, Celastraceae, Chenopodiaceae, Leguminosae (Ingae), Malpighiaceae, Polygalaceae, Sapotaceae y Vitaceae. D'Orbignyana 8: 1-82.

Pire, S.M.; Anzotegui, L.M; Cuadrado, G.A. 1998. Flora Polínica del Nordeste Argentino. Volumen 1. Ed. EU.DE.NE.

Pire, S.M., Anzotegui, L.M.; Cuadrado, G.A. 2001. Flora Polínica del Nordeste Argentino. Volumen 2. Ed. EU.DE.NE.

Pire, S.M., Anzotegui, L.M.; Cuadrado, G.A. 2006. Flora Polínica del Nordeste Argentino. Volumen 3. Ed. EU.DE.NE.

Pire, S.M.; Anzotegui, L.M; Cuadrado, G.A. 2013. Flora Polínica del Nordeste Argentino. Volumen 4. Ed. EU.DE.NE.

Punt, W; Hoen, P.P.; Blackmore, S.; Nilsson S.; Le Thomas, A. 2007. Glossary of pollen and spore terminology. Review of Palaeobotany and Palynology 143: 1-81.

Roulston, T.H.; Cane, J.H. 2000. Pollen nutritional content and digestibility for animals. PlantSyst. Evol. 222: 187209.
Salgado, C.R. 2006. Flora melífera de la provincia de Chaco. Editado por PROSAP y Ministerio de Producción del Chaco, $60 \mathrm{p}$.

Salgado, C.R. 2016.Caracterización botónica y geográfica de las mieles producidas por Apis mellifera L. en la provincia del Chaco, a partir de su composición polinica y parámetros fisico-químicos. Universidad Nacional del Nordeste. Fac. Ciencias Agrarias, UNNE- IBONE. $P h D$ Thes., $201 \mathrm{p}$.

Salgado, C.R.; Maidana, J.F. 2014. Physicochemical characterisation of honey produced in the Chaco province (Argentina). Revista de la Facultad de Ciencias Agrarias UNCUYO 46(2): 191-201.

Salgado, C.R.; Pire, S.M. 1998. Análisis polínico de mieles del Noroeste de la provincia de Corrientes (Argentina) Darwiniana 36 (1-4): 87-93.

Salgado, C.R.; Pire, S.M. 1999. Contribución al conocimiento del contenido polínico de mieles de Corrientes (Argentina). Ameghiniona, A.P.A. publicación especial 6: 95-99.

Salgado, C.R.; Pieszko, G. y M.C. Tellería. (2014). Aporte de la melisopalinología al conocimiento de la flora melífera de un sector de la Provincia Fitogeográfica Chaqueña, Argentina. Boletín de la Sociedad Argentina de Botánica 49: 513-524.

Salgado, C.R.; Tellería, M.C.; Coronel, J.M. 2017. Botanical and geographical origin of honey from the dry and humid Chaco Ecoregiones (Argentina).Grana.ISSN: 0017-3134 (Print) 1651-2049 (Online) Journal homepage: http://www.tandfonline.com/loi/sgra20.

Schmidt, J.O. 1984. Feeding preferences of Apis mellifera L. (Hymenoptera: Apidae): individual versus mixed pollen species. Journal of the Kansas Entomological Society 57 (2): 323-327.

Shaw D.E. (1999). Bees and fungi, with special reference to certain plant pathogens.Australasian Plant Pathology 28:269-282.

Somerville D.C.; Nicol, H.I. 2006. Crude protein and amino acid composition of honey bee-collected pollen pellets from south-east Australia and a note on laboratory disparity. Australian Journal of Experimental Agriculture 46: 141-149.

Stanley R.G.; Linskens H.F. 1974. Pollen. Biology, Biochemistry, Management. Springer-Verlag, Berlin, 307p.

Tamame, M.A. 2011. Estudio de la composición: disponibilidad y calidad de los recursos apícolas del Noroeste de La Pamap, provincia Fitogeográfica del Monte. Tesis Doctoral.

Tellería, M.C. 1993. Floraison et recolte du pollenpar las abeilles domestiques (Apis mellifera L. var. ligustica) dans la pampa argentine. Apidologie 24: 109-120.

Tellería, M.C. 1995. Plantas de importancia apícola del Distrito Oriental de la Región Pampeana (Argentina) Boletín de la Sociedad Argentina de Botánica 30 (3-4): 131-136. 
ANEXO. Ilustraciones

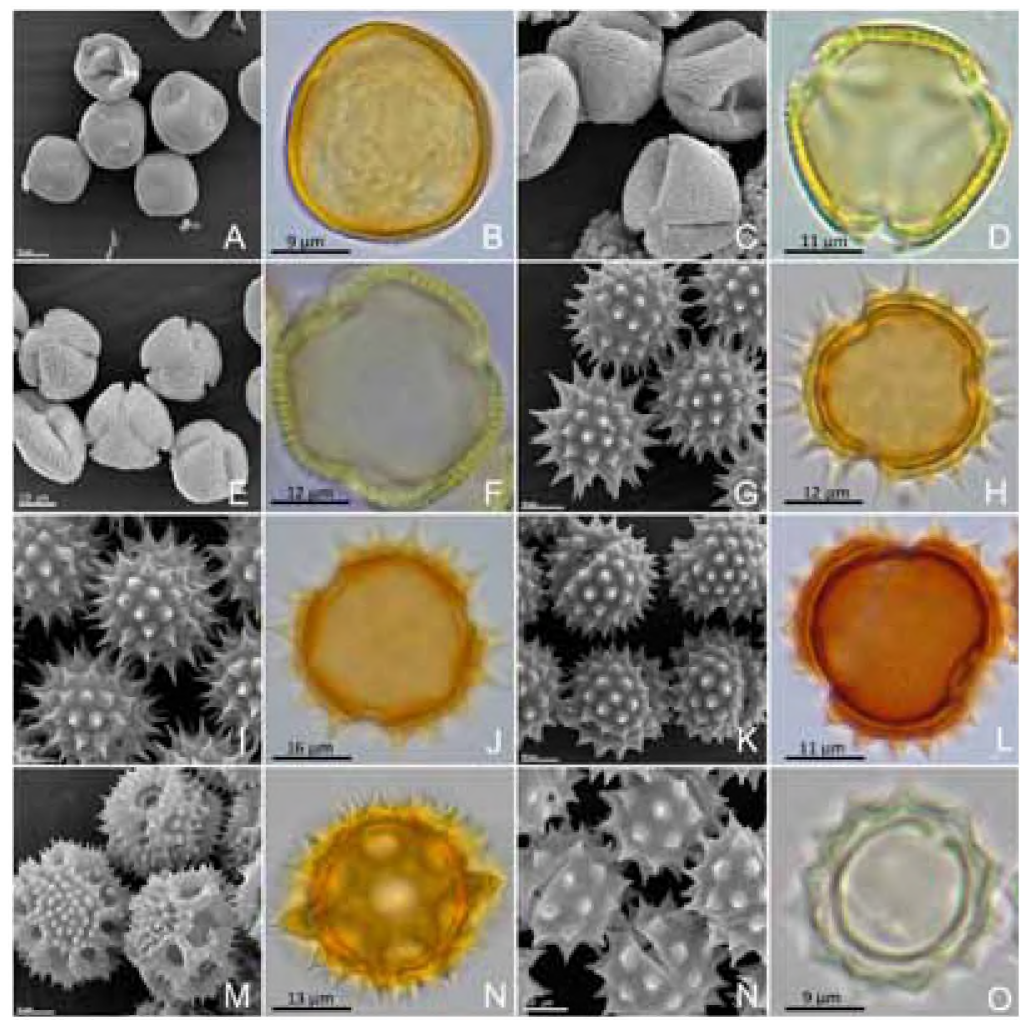

Ilustración 1. Fotografías con microscopio electrónico de barrido y óptico de las especies registradas en cargas corbiculares. A-B. Achatocarpus praecox. C-D. Shinus molle. E-F. Schinopsis lorentzii. G- H. Verbesia sp. I-J. Helianthus annuus. K-L. Senecio grisebachii. M-N. Taraxacum sp. y N-O. Tipo BaccharisEupatorium.

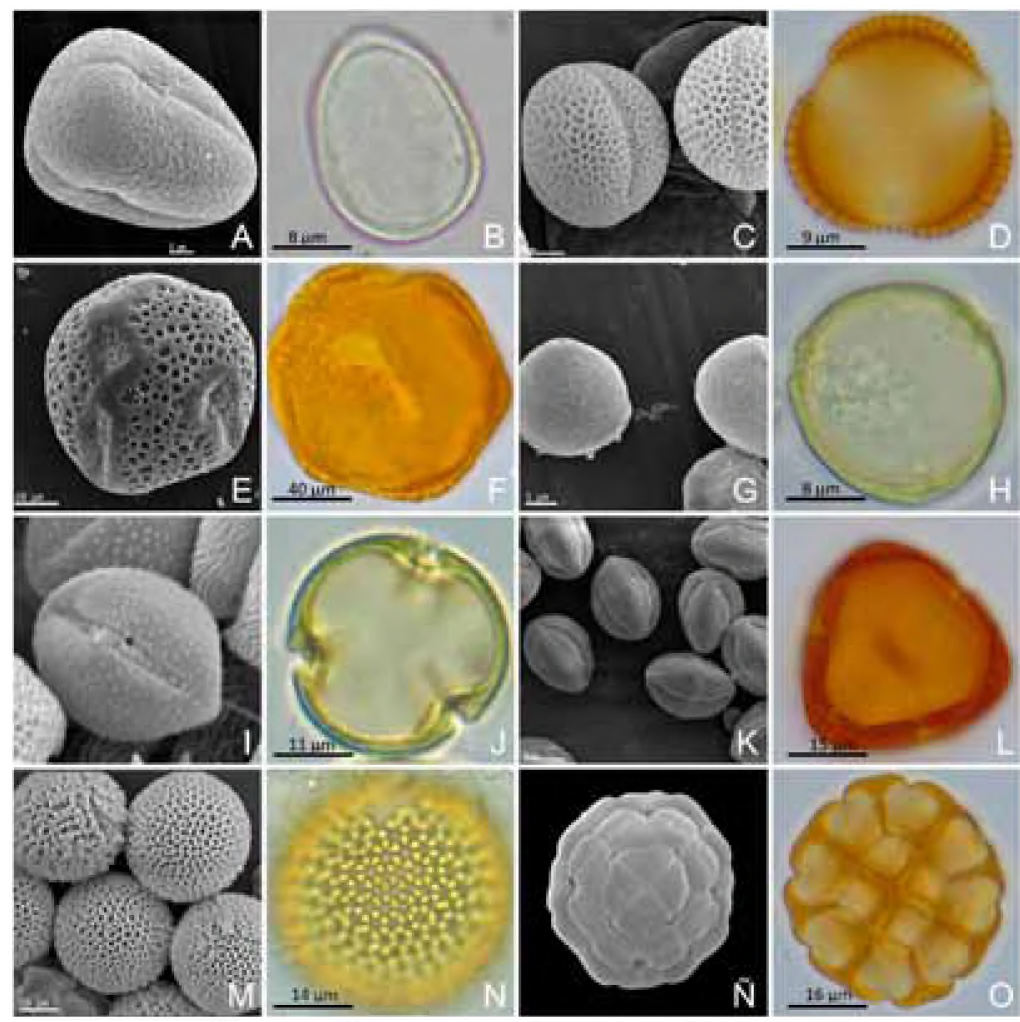

Ilustración 2. Fotografías con microscopio electrónico de barrido y óptico de las especies registradas en cargas corbiculares. A-B. Echium plantagineum. C-D. Brassica napus. E-F. Opuntia quimilo. G-H. Celtis tala. I-J. Cynophalla retusa. K-L. Sapium haematospermum. M-N. Croton sp. N-O. Acacia aroma. 


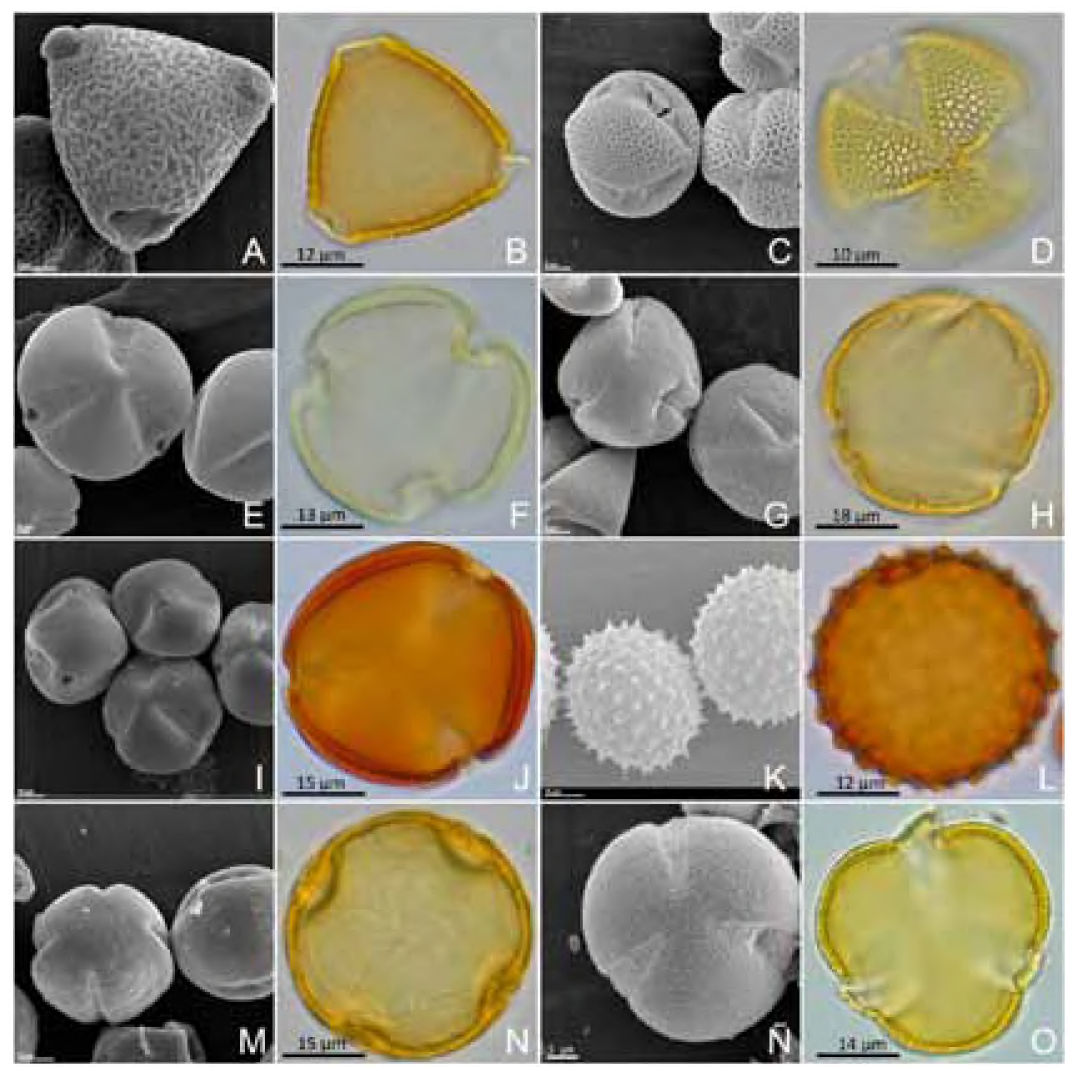

Ilustración 3. Fotografías con microscopio electrónico de barrido y óptico de las especies registradas en cargas corbiculares. A-B. Erythrina crista-galli. C-D. Gleditzia amorphoides. E-F. Prosopis alba. G-H. Prosopis ruscifolia. I-J. Prosopis sp. K-L. Sphaeralcea bonariensis. M-N. Melia azedarach. Ñ-O. Pisonia zapallo.

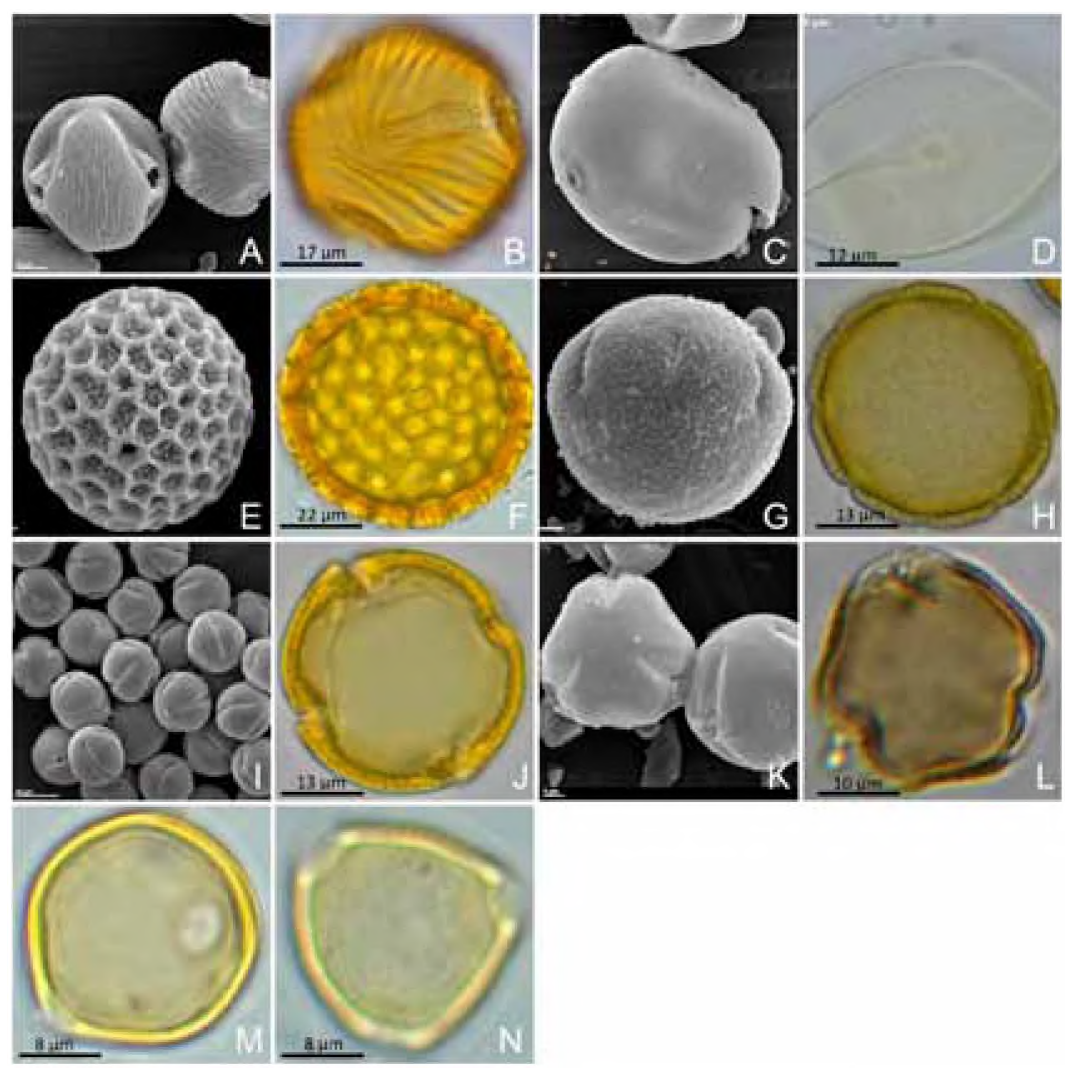

Ilustración 4. Fotografías con microscopio electrónico de barrido y óptico de las especies registradas en cargas corbiculares. A-B. Indeterminado 3c. C-D. Zea mays. E-F. Polygonum hidropiperoides. G-H. Borreria verticillata. I-J. Citrus sp. K-L. Aloysia sp. M-N. Glycine max. 


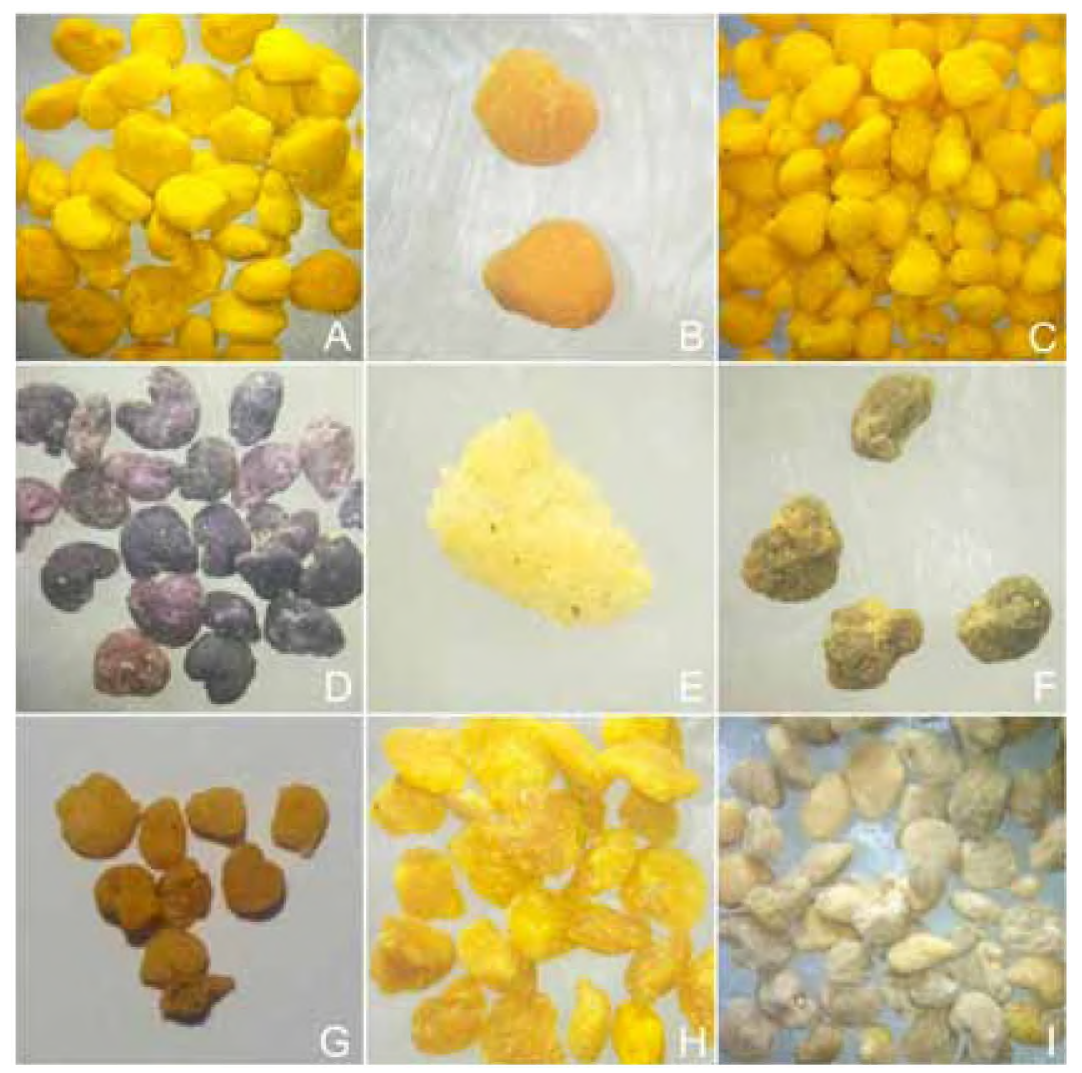

Ilustración 5. Cargas corbiculares en las que se observó correspondencia con un único origen floral. A Schinopsis lorentzii. B. Taraxacum sp. C. Helianthus annuus. D. Echium plantagineum. E. Opuntia quimilo. F. Erythrina crista-galli. G. Sapium haematospermum. H. Zea mays e I. Borreria verticillata.

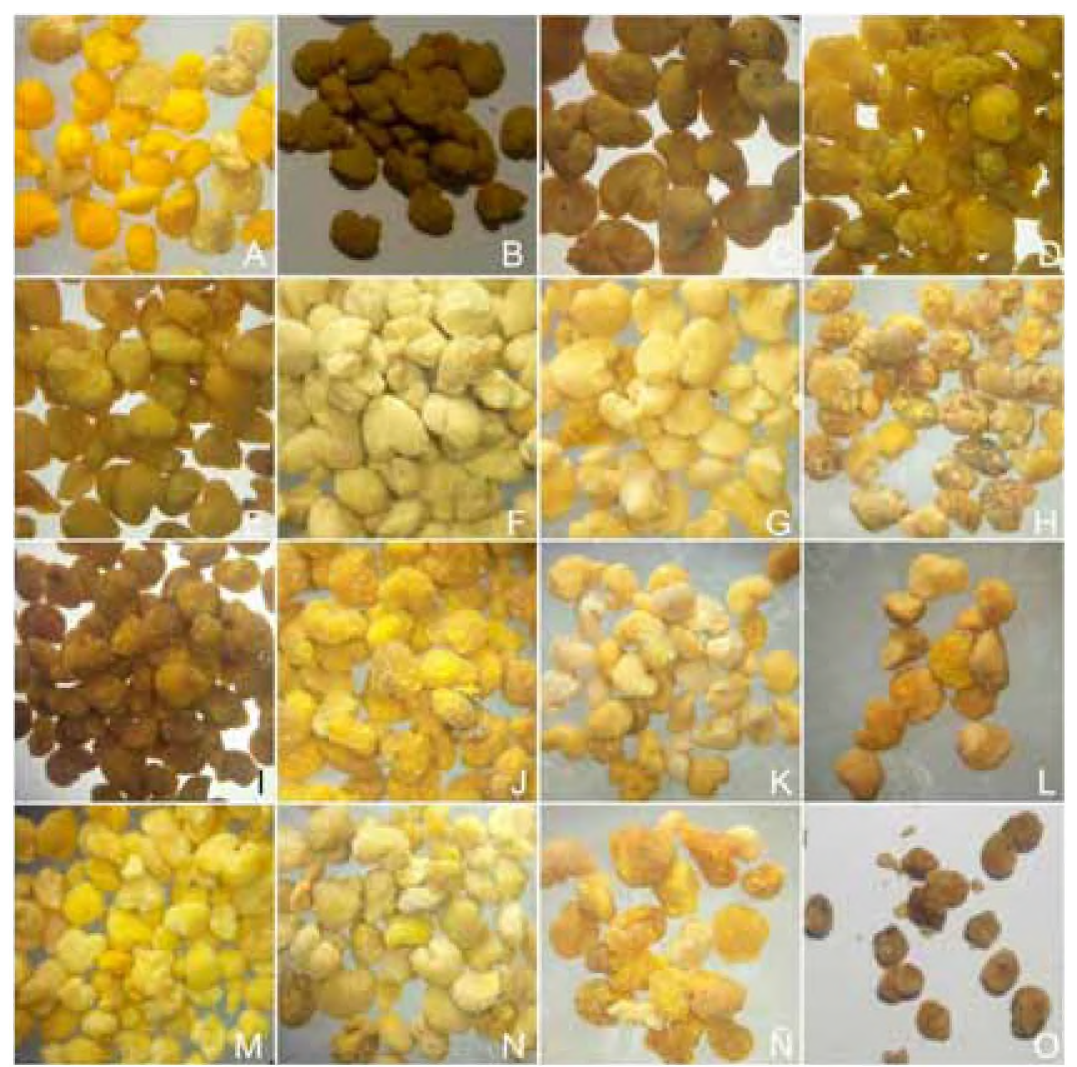

Ilustración 6. Cargas corbiculares de especies que presentaron más de un color. A-B. Senecio grisebachii. C-D. Brassica napus. E-F. Prosopis alba. G-H. tipo Croton sp. I-J. Sphaeralcea bonariensis. K. Acaccia aroma. L. Prosopis ruscifolia. M.N.Ñ. Tipo Baccharis-Eupatorium y O. Gleditzia amorphoides. 


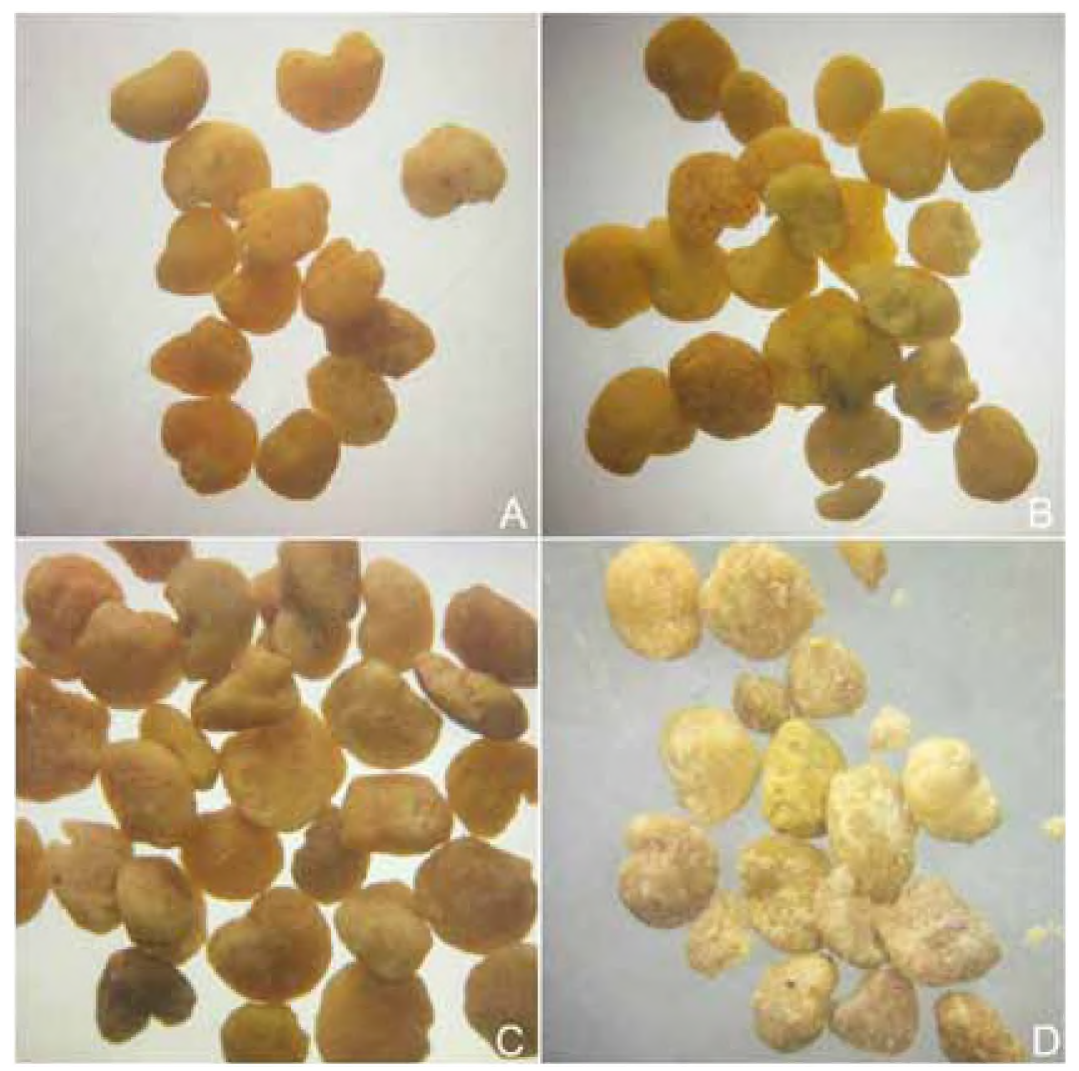

Ilustración 7. Cargas corbiculares que presentaron el mismo color sin embargo pertenecen a especies diferentes. A. Achatocarpus praecox. B. Celtis tala. C. Prosopis sp. y D. Melia azedarach. 